This is a self-archived version of an original article. This version may differ from the original in pagination and typographic details.

Author(s): Tou, Yuji; Watanabe, Chihiro; Moriya, Kuniko; Neittaanmäki, Pekka

Title: Harnessing soft innovation resources leads to neo open innovation

Year: 2019

Version: Accepted version (Final draft)

Copyright: @ 2019 Published by Elsevier Ltd.

Rights: CC BY-NC-ND 4.0

Rights url: https://creativecommons.org/licenses/by-nc-nd/4.0/

Please cite the original version:

Tou, Y., Watanabe, C., Moriya, K., \& Neittaanmäki, P. (2019). Harnessing soft innovation resources leads to neo open innovation. Technology in Society, 58, Article 101114.

https://doi.org/10.1016/j.techsoc.2019.01.007 


\section{Accepted Manuscript}

Harnessing soft innovation resources leads to neo open innovation

Yuji Tou, Chihiro Watanabe, Kuniko Moriya, Pekka Neittaanmäki

PII: $\quad$ S0160-791X(18)30311-7

DOI: $\quad$ https://doi.org/10.1016/j.techsoc.2019.01.007

Reference: TIS 1114

To appear in: Technology in Society

Received Date: 25 November 2018

Revised Date: 20 January 2019

Accepted Date: 24 January 2019

Please cite this article as: Tou Y, Watanabe C, Moriya K, Neittaanmäki P, Harnessing soft innovation resources leads to neo open innovation, Technology in Society (2019), doi: https://doi.org/10.1016/ j.techsoc.2019.01.007.

This is a PDF file of an unedited manuscript that has been accepted for publication. As a service to our customers we are providing this early version of the manuscript. The manuscript will undergo copyediting, typesetting, and review of the resulting proof before it is published in its final form. Please note that during the production process errors may be discovered which could affect the content, and all legal disclaimers that apply to the journal pertain. 


\title{
Harnessing Soft Innovation Resources Leads to Neo Open Innovation
}

\author{
Yuji Tou $^{a}$, Chihiro Watanabe ${ }^{b, c}$, Kuniko Moriya $^{b, d}$, Pekka Neittaanmäki ${ }^{b}$ \\ ${ }^{a}$ Tokyo Institute of Technology, Japan \\ ${ }^{b}$ Faculty of Information Technology, University of Jyväskylä, Finland \\ ${ }^{c}$ International Institute for Applied Systems Analysis (IIASA), Austria \\ ${ }^{d}$ Research and Statistics Department, Bank of Japan, Japan
}

\begin{abstract}
Advancement of the digital economy has transformed the concept of the growth crossover in nations and firms, both concerning input and output. Advanced economies have been confronting a dilemma between input increases and output decreases. Contrary to traditional expectations, excessive increase in input has resulted in a productivity decline in output. A solution to this dilemma can only be expected by harnessing the vigor of soft innovation resources that lead to neo open innovation in the digital economy. This paper attempts to demonstrate this hypothetical view. Based on an empirical analysis of the development trajectories of 140 countries and 500 global ICT firms, dynamism, resulting in bipolarization between a virtuous cycle and a vicious cycle between input increases and productivity enhancement, was discovered. Furthermore, an empirical analysis focusing on the development trajectories of two world ICT leaders, Finland and Singapore, identified a mechanism of neo open innovation that assimilates soft innovation resources into a national production system. This mechanism can substitute for research and development (R\&D) and removes structural impediments to growth while providing relief from the increasing burden of $R \& D$ investment. The above findings provide insightful suggestions for drafting a roadmap towards neo open innovation in the digital economy.
\end{abstract}

Keywords: Digital economy; productivity decline; dilemma; soft innovation resources; neo open innovation

Corresponding author:

Chihiro Watanabe (watanabe.c.pqr@gmail.com) 


\section{Introduction}

Advances in information and communication technology (ICT) have generated the digital economy. This can largely be attributed to the dramatic advancement of the Internet. The further progression of digitalized innovation over the last two decades, such as mobile services, particularly of smartphones, has augmented this generation significantly.

The Internet promotes a free culture, the consumption of which provides utility and happiness to people but cannot be captured through the GDP that measures revenue (Lowrey, 2011). Authors have defined this Internet-driven added value as uncaptured GDP (Watanabe et al., 2015a). The shift in people's preferences from economic value to supra-functionality beyond economic value (encompassing social, cultural, and economic values) (MacDonagh, 2008) induces the further advancement of the Internet, which intensifies the increasing dependence on uncaptured GDP.

Thus, the technological shift from the computer age to the Internet and the abundance of freely available digital products and services in the digital economy (Brynjolfsson et al., 2014) has resulted in a new co-evolution among people's shifting preferences, the advancement of the Internet, and the increasing dependence on uncaptured GDP (Watanabe et al., 2015a).

Based on these findings, the authors have demonstrated the spinoff dynamism from traditional computer-initiated ICT innovations in the era of the Product of Things (PoT) to the Internet-initiated ICT innovations in the Internet of Things (IoT) (McKinsey Global Institute, 2015), as illustrated in the upper part of Fig. 1 (Watanabe et al., 2015b, $2016 a$ ).

In this Internet-initiated ICT innovation, bipolarization between ICT-advanced economies and ICT-developing economies has become a crucial issue. This can be attributed to the two-faced nature of ICT, that is, while the advancement of ICT generally contributes to the enhanced prices of technology through a new functionality development, the dramatic advancement of the Internet reacts to decreased prices of technology according to its nature, including freebies, easy replication, and mass standardization (Cowen, 2011; Watanabe et al., 2015b).

Since the decrease of prices corresponds to the decline of the marginal productivity of technology, given the maximum profit seeking in the competitive environment, ICT-advanced economies confront a dilemma between ICT increase and productivity decline. 
A solution to this dilemma can only be expected by harnessing the vigor of soft innovation resources, which are a condensate and crystal of the advancement of the Internet (Tou et al., 2018a, 2018c). Soft innovation resources arouse and activate latent self-propagating functions of ICT, which induce functionality development, leading to a supra-functionality beyond economic value that corresponds to people's shift in preferences, as illustrated in the lower part of Fig. 1.

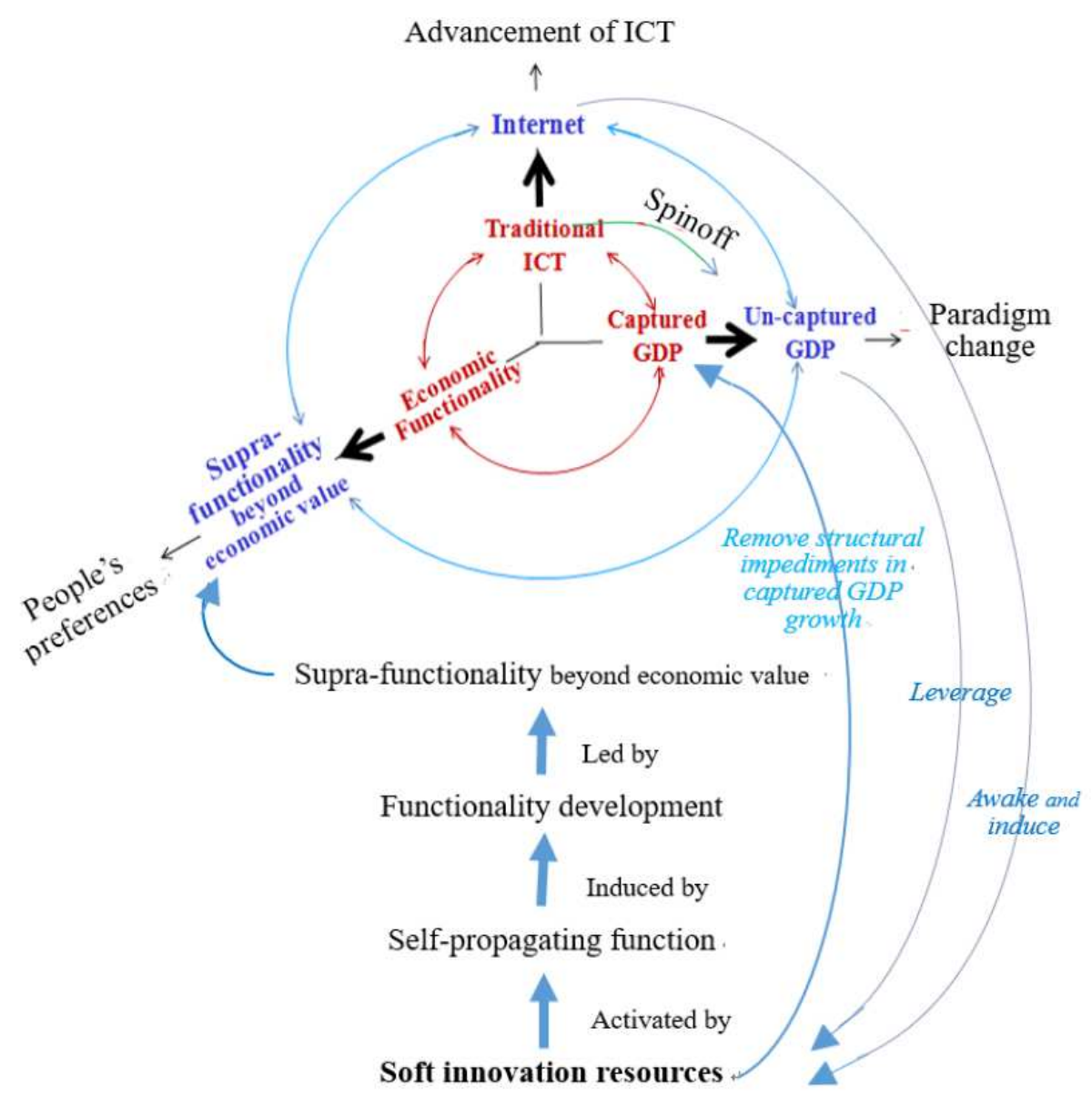

Fig. 1. The Hybrid Role of Soft Innovation Resources.

Thus, the survival strategy of ICT-advanced economies against the foregoing dilemma reacts to the spontaneous creation of uncaptured GDP and leverages the emergence and utilization of soft innovation resources. The advancement of the Internet, induced by a preferences shifting to a supra-functionality beyond economic value, awakens and induces soft innovation resources, as they are a condensate and crystal of the advancement of the Internet.

The recent resurgence of GDP growth in Finland, independent of research and development (R\&D) increase, can be attributed to soft innovation resources, such as trust between the public, employers, and labor union, based on the Competitiveness Pact in 2016, which removed structural impediments to GDP growth (Tou et al., 2018b). 
All of this suggests the hybrid role of soft innovation resources in devising hybrid co-evolutional innovation among the advancement of ICT, paradigm change, and people's shift in preferences.

This hybrid role enables the provision of a solution to the dilemma that ICT-advanced economies have been confronting and leads to neo open innovation in the digital economy. 
To date, while many studies have analyzed identical economic behaviors of the nations and ICT firms in the digital economy and identified unique features of their behaviors (e.g., Ahmad et al., 2016; Dervis et al., 2016; The US Council on Competitiveness, 2016; The World Bank, 2016; Byrne et al., 2016; Feldstein, 2017; EU, 2017b; IMF, 2017b; Kahre et al., 2017; Bloomberg, 2018), none have demonstrated the foregoing hypothetical view.

Inspired by the foregoing, spinning-off, co-evolutional innovation among ICT advancements, paradigm shifts, and people's preferences, this paper attempts to demonstrate this hypothetical view. Based on an intensive review of preceding studies and an empirical analysis of the development trajectories of 140 countries and 500 global ICT firms, dynamism resulting in bipolarization between a virtuous cycle and a vicious cycle between input increases and productivity enhancement was discovered. Furthermore, an empirical analysis, focusing on the development trajectories of two world ICT leaders, Finland and Singapore, identified a mechanism of neo open innovation that assimilates soft innovation resources into a national production system. This mechanism substitutes for $R \& D$ and removes structural impediments to growth while providing relief from the increasing burden of $R \& D$ investment.

The above findings provide insightful suggestions for drafting a roadmap towards neo open innovation in the digital economy.

The structure of this paper is as follows. Section 2 discusses unique features of ICT. Section 3 analyzes neo open innovation in the digital economy. The hybrid role of soft innovation resources is analyzed in Section 4. The mechanism of the hybrid role of soft innovation resources is investigated in Section 5. Finally, Section 6 summarizes the noteworthy findings, policy suggestions, and future research. 


\section{Unique Features of ICT}

\subsection{Simultaneous Dissemination}

The digitalization of the economic activity can be broadly defined as the incorporation of data and the Internet into production processes and products, new forms of household and government consumption, fixed-capital formation, cross-border flows, and finance (IMF, 2018a).

Consequently, this activity is subject to unique features of ICT, centered on the advancement of the Internet. This feature can be characterized as simultaneous dissemination, logistic growth, and the two-faced nature of price formation.

The simultaneous dissemination features of ICT can be attributed to the Internet's functional features of self-propagating permeation, homogeneous ICT stock creation, and co-evolutionary advancement with new functional devices.

\section{(1) Self-propagating Permeation}

The dramatic advancement of the Internet has generated the digital economy, which has changed the way business is conducted and daily life (Tapscott, 1994). The further progression of digitized innovation over the last two decades, such as cloud services, mobile services, and artificial intelligence, has augmented this change significantly. This has accelerated the permeation of the Internet into ICT in general (Watanabe et al., $2018 c$ ), and has provided us with unprecedented services and conveniences (DBCDE, 2009).

\section{(2) Homogeneous ICT Stock Creation}

Such permeation creates homogeneous ICT stock that plays a locomotive power in the IoT society.

By means of a bibliometric approach, authors traced the trend in the transforming factor of R\&D into ICT stock ${ }^{1}$ in 27 ICT-related key scientific research articles consisting of (i) Internet $R \& D$, (ii) Internet-related peripheral $R \& D$, and (iii) other ICT R\&D over the period of 1980-2015 (see the details in Watanabe et al., 2018c). Above analysis demonstrated that while the values of the transformation factor were diverged by 2005 , they have been converging through 2010-2015; thereby, technology stock, both of the Internet and other broad ICT, can be treated as a sum of respective R\&D that is leading to homogeneous ICT stock creation.

\section{(3) Co-evolutionary Advancement with New Functional Devices}

The dramatic advancement of the Internet and its further progression of digitized innovation have augmented the permeation of the Internet into not only broad ICT but also into all production factors leading to an IoT society (Watanabe et al., 2018a).

In this permeation process, digitalized innovation mutually stimulates each other, leading to co-evolutionary dynamics, and creates a new social ecosystem (OECD, 2016).

1 ICT stock, $T$, can be approximated by the ratio of R\&D expenditure, $R$, and the transforming factor, $\chi$, as $T \approx R / \chi$ in the long term, where $\chi=\rho$ (rate of the obsolescence of technology) $+g$ (growth rate of $R$ at the initial state). See more details in Section 3. 
This is quite similar to the co-evolutionary development of personal computers (PCs) and printers through coopetition (cooperation and competition) strategies in the 1990s, as illustrated in Fig. 2.

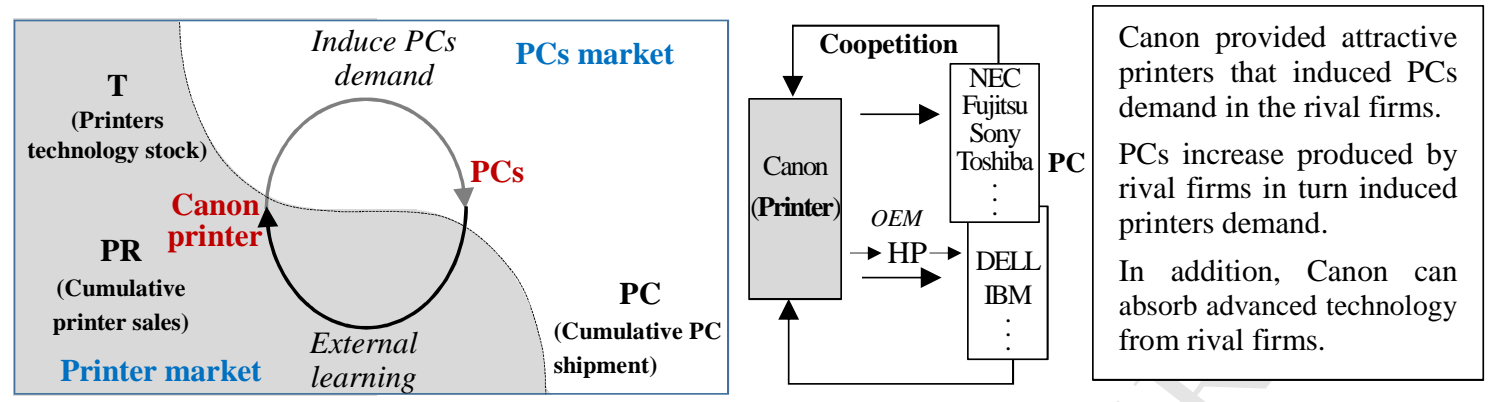

Fig. 2. Co-evolutionary Development of Canon Printers and PCs: Coopetition.

Source: Watanabe et al. (2009).

Fig. 3 demonstrates the correlation between the ratio of the GDP per capita and Internet use and the ratio of smartphone ownership in 40 countries (11 countries in advanced economies $(A E)$ and 29 countries in emerging and developing economies $(E D E)$ ) in 2015, respectively.

D1 11 advanced countries

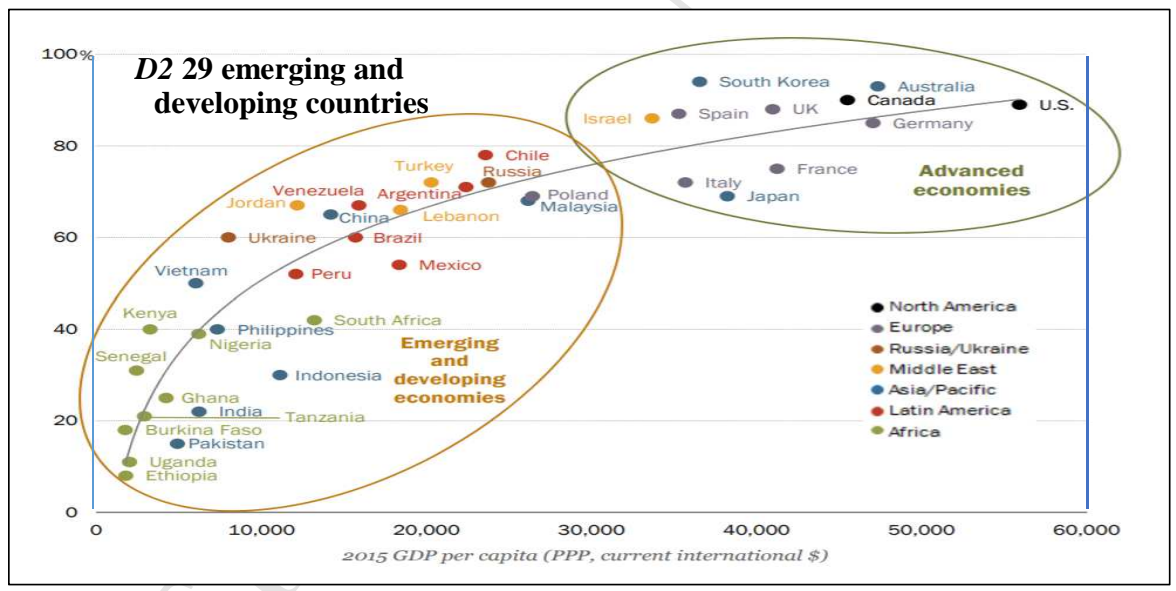

Fig. 3-1. The Correlation between the GDP Per Capita and Internet Usage Ratio in 40 Countries (2015).

Source: Pew Research Center (2016).

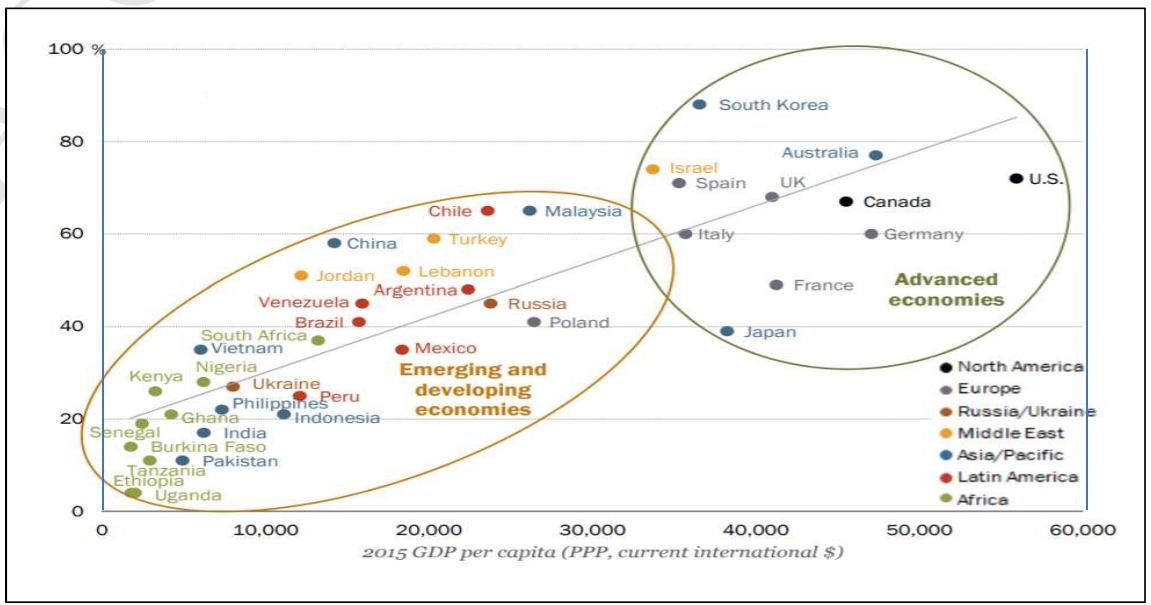




\section{Fig. 3-2. The Correlation between the GDP Per Capita and Smartphone Ownership Ratio in 40 Countries (2015).}

Source: Pew Research Center (2016).

Fig. 3 demonstrates that ICT simultaneously permeates into 40 countries, regardless of economic development stage. Previously, a delay in economic development was a fundamental impediment in emerging and developing economies, resulting in a vicious cycle between economic development and technological advancement. However, Fig. 3 demonstrates that countries in emerging and developing economies enjoy the Internet and smartphone usage, notwithstanding their low level of economic development.

Moreover, Fig. 4 demonstrates that, contrary to traditional technology, the discrepancy of the speed of dissemination of advanced ICT, such as the Internet and mobile phones, between high-income countries and low-income countries has dramatically decreased.

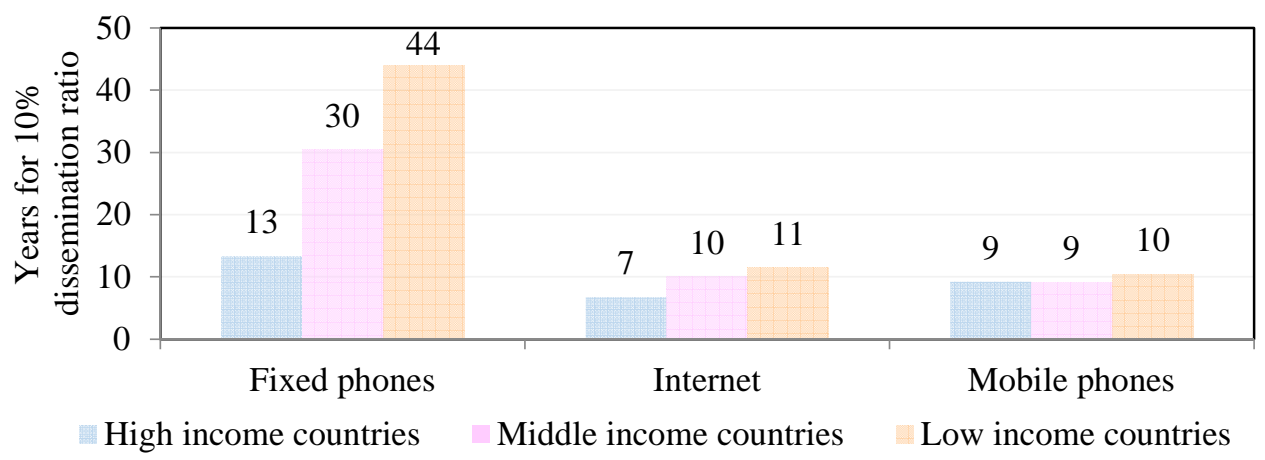

Fig. 4. Years of a 10\% Dissemination Ratio for Fixed Phones, Internet, and Mobile Phones by Income Level.

Source: White Paper on Japan's Information and Communication (2011).

Such simultaneous worldwide dissemination creates a new, ICT-driven social ecosystem (UNESCO, 2015). In this dissemination process, digitalized innovation mutually stimulates each other, leading to co-evolutionary dynamics, and creates a new social ecosystem. Fig. 5 and Table 1 demonstrate a strong correlation between Internet use and smartphone ownership in 40 countries regardless of economic level. Such a strong correlation stimulates the co-evolutionary development of ICT advancement, leading to the creation of a new social ecosystem. 


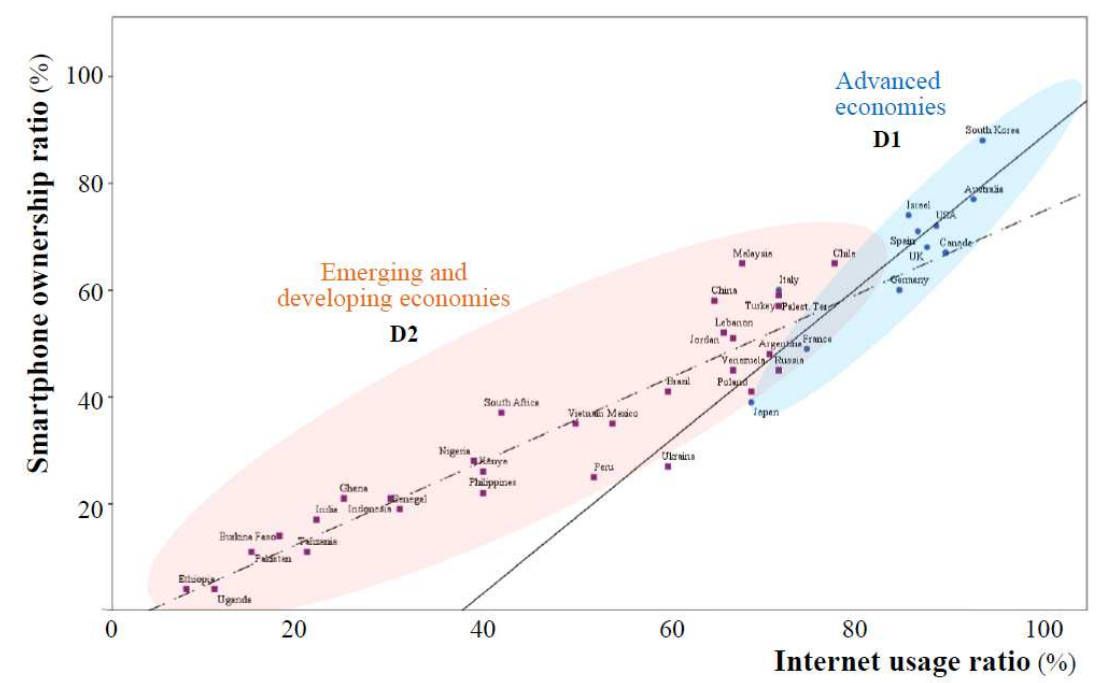

Fig. 5. The Correlation between Internet Usage and Smartphone Ownership in 40 Countries (2015).

Table 1 The Correlation between Internet Usage and Smartphone Ownership in 40 Countries (2015)

$$
\begin{gathered}
\ln \boldsymbol{S P}=-0.941+1.153 D_{1} \ln \boldsymbol{I D}+1.147 \ln D_{2} \boldsymbol{I D} \\
(-4.31)
\end{gathered}
$$

adj. $R^{2} 0.933$

$S P$ : Smartphone ownership ratio; $I D$ : Internet usage ratio; $D$ : Dummy variables $\left(D_{1}: A E=1, E D E=0 ; D_{2}\right.$ : $A E=0, E D E=1)$.

The figures in parentheses indicate t-statistics; all are significant at the $1 \%$ level.

All of these demonstrate ICT's simultaneous dissemination crossover to a techno-economy, and this can be seen as one of the unique feature of ICT.

\subsection{Logistic Growth}

Logistic growth nature is identical feature of ICT. Simultaneous dissemination of ICT centered on the advancement of the Internet as reviewed in the preceding sub-section highlights logistic development and diffusion, bi-polarization fatality, and self-propagating potential.

\section{(1) Logistic Development and Diffusion}

ICT in which network externalities function to alter the correlation between innovations and institutional systems which creates new features of the innovation leading to exponential increase (Watanabe et al., 2004). Schelling (1998) portrayed an array of logistically developing and diffusing social mechanisms stimulated by these interactions. Advancement of the Internet further stimulates these interactions and accelerates ICT's logistically developing and diffusing feature.

\section{(2) Bi-polarization Fatality}

Given the logistic development and diffusion, ICT-driven growth follows a sigmoid trajectory which continues to grow until it reaches carrying capacity (upper limit of growth). In this trajectory, while growth rate continues to increase before reaching to inflection point corresponding to the half level of carrying capacity, it changes to 
decrease after exceeding the inflection point. Thus, contrary to simultaneous dissemination, ICT-driven logistic growth incorporates bi-polarization fatality, increase and decrease of marginal productivity between before and after the inflection point.

Fig. 6 demonstrates development trajectories in 140 countries in the world and 500 global ICT firms in 2016 taking ICT advancement and its marginal productivity to GDP per capita and sales, respectively. Fig. 6 demonstrates clear bi-polarization between ICT-growing economies and ICT-advanced economies. While the former enjoys a virtuous cycle between ICT advancement and productivity increase, the latter suffers a vicious cycle as further ICT advancement results in productivity decrease.
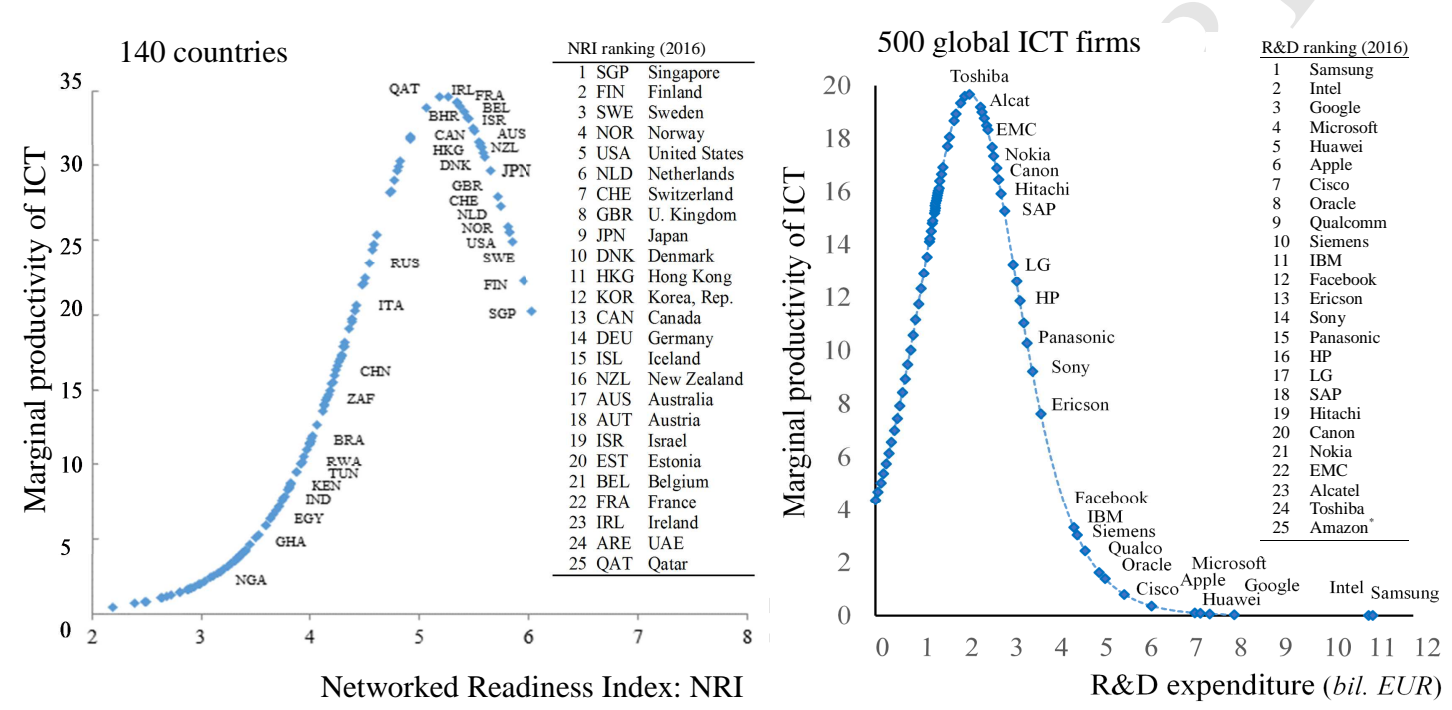

Fig. 6. Development Trajectories in 140 Countries in the World and 500 Global ICT Firms (2016).

*Amazon is included in the list as its market capitalization is conspicuous while R\&D investment is ranked lower than 25 countries in 2016.

Sources: World Economic Outlook (IMF, 2017a); Global Information Technology Report 2016 (World Economic Forum, 2016); Economics of Industrial Research and Innovation (EU, 2017a).

\section{(3) Self-propagating Potential}

While growth will stagnate as growth rate decreases after the inflection point and closing to the upper limit in the ICT-driven growth, in particular innovations, the correlation of interaction between innovation and institutions display a systematic change in the process of growth and maturity. This leads to the creation of a new higher carrying capacity in the processes of its development. This functions to enhance the level of carrying capacity as development proceeds. This suggests that ICT-driven growth incorporates self-propagating potential (Watanabe et al., 2004). Arose and activation of this potential may provide a solution to productivity decrease as a consequence of bi-polarization fatality.

\subsection{The Two-faced Nature of Prices Formation}




\section{(1) The Two-faced Nature}

Advanced ICT, initiated by the advancement of the Internet, incorporates a contrasting nature, bipolarization derived from its two-faced nature with respect to price formation. While the advancement of ICT generally contributes to the enhanced prices of technology through the development of new functionality, the dramatic advancement of the Internet reacts to decreased prices of technology due to its nature, consisting of freebies, easy and free replication, and mass standardization (Watanabe et al., 2015b). Thus, advancement of the Internet beyond a certain level reverses the increasing prices to decreasing prices. These prices are equivalent to the marginal productivity of ICT under the maximum profit option in the competitive circumstances. This corresponds to the aforementioned bi-polarization fatality, stemming from logistic growth.

Fig. 7 illustrates this dynamism regarding 500 global ICT firms that demonstrate bipolarization between price increase and decrease, depending on the ICT advancement.

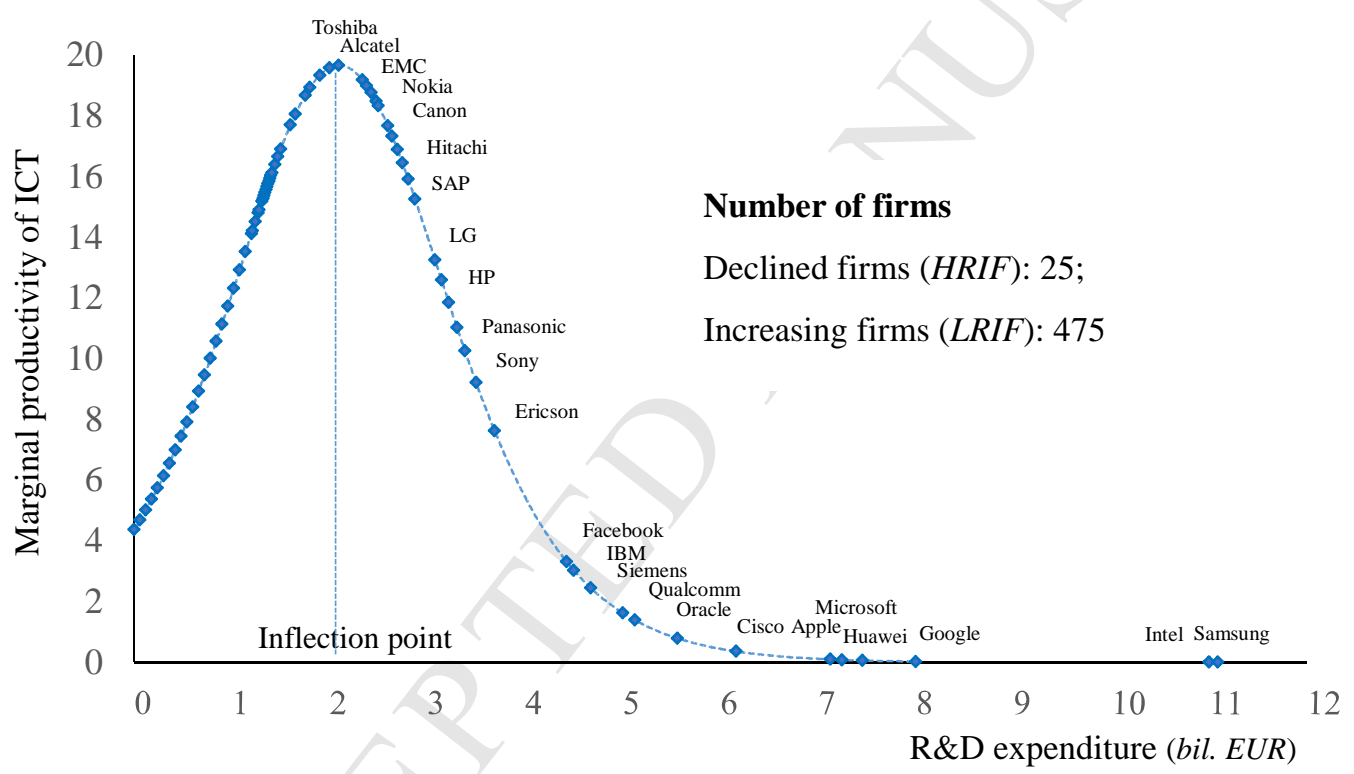

Fig. 7. The Comparison of the Marginal Productivity of ICT in 500 Global ICT Firms (2016).

Original sources: Naveed et al. (2018) and Watanabe et al. (2018a).

Consequently, such bipolarization has become inevitable in the competitive game of global ICT firms. Provided that these firms seek to maximize profit in the competitiveness market, prices decrease as a consequence of the excessive ICT advancement results in their marginal productivity of ICT decline. Fig. 6 also demonstrates such phenomena concerning 500 global ICT firms in 2016. This figure demonstrates explicit bi-polarization between high R\&D-intensive firms (HRIFs) and the remaining low R\&D-intensive firms (LRIFs). HRIFs have fallen into a vicious cycle between R\&D expenditure centered on ICT and its marginal productivity, as the former's increase results in a decline for the latter. On the contrary, LRIFs have maintained a virtuous cycle, as an $R \& D$ increase leads to marginal productivity 
increase.

This bipolarization nature stemming from the two-faced nature of ICT is another unique feature of ICT. Productivity has declined in ICT-advanced countries in the digital economy (Watanabe et al., 2018a, 2018c), and recent fears of stagnating trends in ICT giants (The Economist, 2018) can be attributed to this feature.

\section{(2) Dilemma}

Global ICT firms have been endeavoring to increase their digital values centered on sales $(S)$ (Watanabe et al., 2018a). The growth rate of sales $(\Delta S / S)$ largely depends on ICT $(T)$ advancement rather than on traditional production factors $(X)$, such as labor $(L)$ and capital $(K)$. ICT's contribution to sales growth can be approximated by the product of the marginal productivity of ICT $(\partial S / \partial T$ : MP) and R\&D intensity, the ratio of R\&D centered on ICT and sales $(R / S): R S^{2}$

Global ICT firms endeavor to achieve sales growth by leveraging ICT's contribution to this growth, consisting of an increase in the marginal productivity of ICT $(M P)$ and $\mathrm{R} \& \mathrm{D}$ intensity $(R S)$. The product of both factors $(M P \times R S)$ represents the contribution of ICT to the sales growth rate. Fig. 8 illustrates this strategy through the stages of global position according to $\mathrm{R} \& \mathrm{D}$ level $(R)$.

$$
\frac{\Delta S}{S}=\sum \frac{\partial S}{\partial X} \cdot \frac{X}{S}+\frac{\partial S}{\partial T} \cdot \frac{R}{S}=\sum \frac{\partial S}{\partial X} \cdot \frac{X}{S}+M P \cdot R S
$$

ICT contribution to sales growth rate $S_{R}=M P$ x $R S \quad$ Taking logarithm $\ln S_{R}=\ln M P+\ln R S$
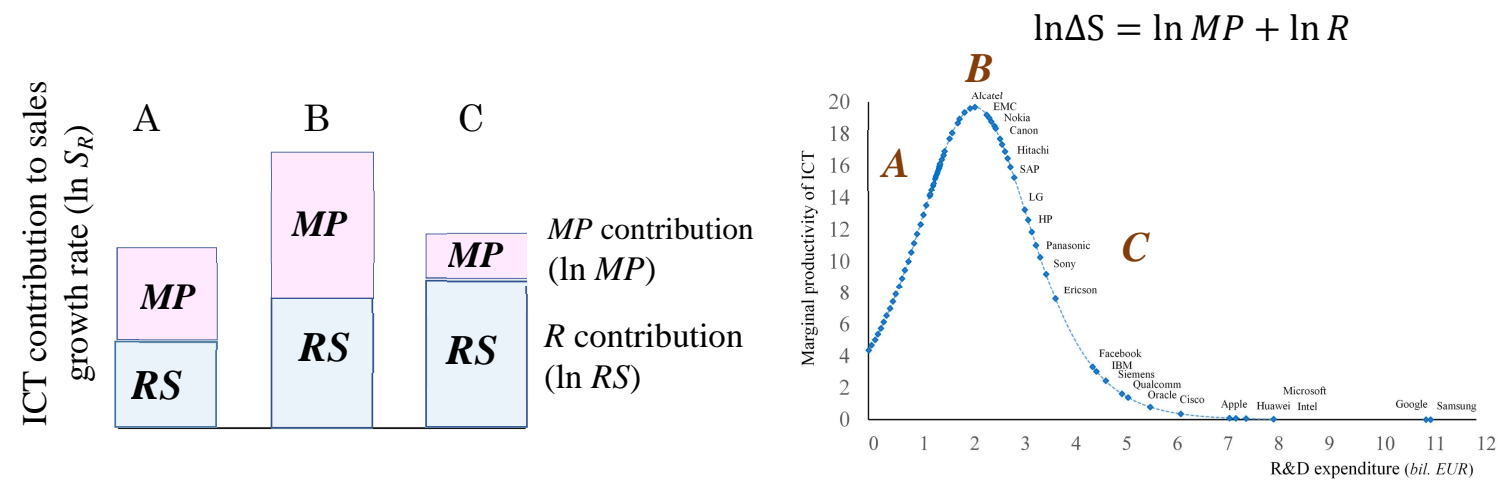

Fig. 8. The Illustration of the ICT-driven Competitiveness Strategy in Global ICT Firms.

This strategy can be attained by constructing a virtuous cycle between $M P$ and $R$ (an $R$ increase leads to an $M P$ increase, which, in turn, induces further $R$ increases), as far as global ICT firms remain LRIFs (stage A in Fig. 8). However, once they move up to $H R I F s$ (stage $\mathrm{B}$ ), they fall into a vicious cycle (an $R$ increase results in declining $M P$ (stage $\mathrm{C}$ )). In this pitfall, $M P$ recovery can be attained by reducing $R$ (moving back to A) which results in diminishing the target sales growth.

$2 \frac{\Delta S}{S}=\sum \frac{\partial S}{\partial X} \cdot \frac{X}{S}+\frac{\partial S}{\partial T} \cdot \frac{R}{S}=\sum \frac{\partial S}{\partial X} \cdot \frac{X}{S}+M P \cdot R S$ 
In order to attain the target sales growth that is essential for the survival of global ICT firms HRIFs should find disruptive innovation solutions to overcoming this dilemma. This solution can be found through:

(i) Incorporation of the vigor of LRIFs that enjoy a virtuous cycle between $R$ and $M P$, and/or,

(ii) Harnessing the vigor of external innovation resources that do not accelerate a vicious cycle.

The former option can be expected by harnessing the vigor of emerging and developing countries (who remain at stage A) that also enjoy the benefit of digital innovation simultaneously. Authors (e.g., Watanabe et al., 2015a) have postulated the significance of co-evolutionary acclimatization strategies for this option, given the possibility of further ICT advancement in the ICT-advanced economies. ${ }^{3}$ However, as confronting the rising capital intensity in ICT-advanced economies subsequently increases the burden of such investment (The Economist, 2018), this option no longer fits reality. The Economist (2018) revealed the serious concern on rising capital intensity of global ICT leaders by pointing out that "Investors love tech stocks for their high margins and low investment. But this view no longer fits reality. For the world top eight ICT firms total investment has tripled since 2013 , to $\$ 180$ bn a year. Internet firms are now the corporate world's largest spenders, but exhibit little of the rigor seen at conventional big investors such as Shell or Intel. The probable result is lower returns as firms throw cash at mediocre new businesses and enter the markets of rivals."

Consequently, the latter option has become a more promising option that can be expected by means of neo open innovation, which harnesses the vigor of soft innovation resources (which are external to $R$ ) corresponding to the digital economy.

The next section discusses the consequences of this option.

\footnotetext{
${ }^{3}$ While ICT-advanced economies enable the further advancement of ICT, this results in the decline of marginal productivity due to a vicious cycle between them in these economies. Thus, such advancement capability should be addressed to the advancement of ICT-growing economies, which enjoy a virtuous cycle between their marginal productivity increases leading to sustainable growth. ICT-advanced economies can harness the fruit of growth in ICT-growing economies thereby co-evolutionary acclimatization between two economies can be expected.
} 


\section{Neo Open Innovation in the Digital Economy}

\subsection{Endeavors against Productivity Decline}

\section{(1) Consequences of R\&D-driven Logistic Growth}

Confronting the aforementioned dilemma, ICT-advanced economies have been endeavoring to find a practical solution by transforming into a new business model.

Given that this dilemma stems from the unique feature of ICT, logistic growth with simultaneous dissemination, as reviewed in Section 2, this feature should be reviewed first (see the details of the mathematical demonstration in the column 1).

Table 2 analyzes ICT-driven developing strategies in 136 countries across the world as well as in 500 global ICT firms in 2016 by comparing their linear growth (model A) and logistic growth (model B).

Table 2 ICT-driven Development Trajectories in 136 Countries and 500 Global ICT firms (2016)

$$
\text { Model A: } \ln V=a+b \ln W \quad \text { Model B: } V=\frac{N}{1+b e^{-a W}}
$$

\begin{tabular}{|c|c|c|c|c|c|c|}
\hline & Model & $N$ & $a$ & $b$ & $\operatorname{adj} . R^{2}$ & Remarks \\
\hline \multirow{2}{*}{136 Countries } & A & & $\begin{array}{c}0.72 \\
(2.05)\end{array}$ & $\begin{array}{c}5.76 \\
(23.06)\end{array}$ & 0.797 & \\
\hline & B & $\begin{array}{c}73.68 \times 10^{3} \\
(6.31)\end{array}$ & $\begin{array}{c}1.88 \\
(7.18)\end{array}$ & $\begin{array}{c}18.40 \times 10^{3} \\
(9.55)\end{array}$ & 0.821 & \\
\hline \multirow{2}{*}{500 ICT firms } & A & & $\begin{array}{c}2.32 \\
(4.43)\end{array}$ & $\begin{array}{c}1.01 \\
(12.40)\end{array}$ & 0.632 & $\begin{array}{l}\text { Dummy } \\
\text { variables } \\
\text { used }\end{array}$ \\
\hline & B & $\begin{array}{c}59.62 \\
(17.39)\end{array}$ & $\begin{array}{c}1.32 \\
(10.98)\end{array}$ & $\begin{array}{l}15.91 \\
(21.87)\end{array}$ & 0.784 & $\begin{array}{l}\text { Dummy } \\
\text { variables } \\
\text { used }\end{array}$ \\
\hline
\end{tabular}

136 countries - V: GDP per capita; $W$ : NRI. 500 companies $-V$ : Sales; $W:$ R\&D expenditure.

The figures in parentheses indicate t-statistics; all are significant at the $1 \%$ level.

Table 2 demonstrates that ICT-driven logistic growth trajectories (model B) were statistically more significant both in the 136 countries and 500 ICT firms examined. Consequently, they are subject to bi-polarization fatality, as reviewed earlier and given the two-faced nature of price formation, they cannot avoid the foregoing dilemma between $R \& D$ increase and productivity decline.

\section{Column 1: Mathematical demonstration}

Digital value $V$ created by in an IoT society can be depicted as follows:

$V=F\left(X, I_{g}\right)$

where $I_{\mathrm{g}}$ : gross ICT stock $=I($ ICT stock $)+J$ (internet dependence);

$X$ : other production factors.

Translog (transcendental logarithmic) expansion on the first term:

$\ln V=p+q \ln X+r \ln I_{\mathrm{g}}$

where $p, q$, and $r$ : coefficients.

$I_{\mathrm{g}}$ embodies into $X$ in an IoT society as follows:

$X=F\left(I_{\mathrm{g}}\right) \quad \ln X=p_{\mathrm{x}}+r_{\mathrm{x}} \ln _{\mathrm{g}}$

where $p_{\mathrm{x}}$ and $r_{\mathrm{x}}$ : coefficients. 
Synchronizing equations (2) and (3):

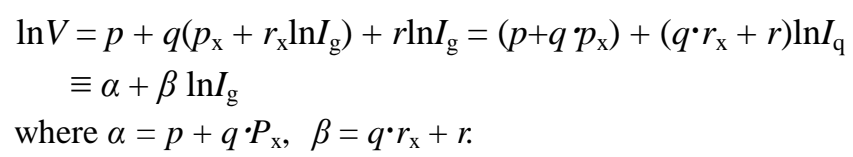

This demonstrates that $V$ is governed by $I_{\mathrm{g}}$ under the above circumstances.

As the Internet permeates into ICT in general, $I_{\mathrm{g}}$ increases proportional to gross $\mathrm{R} \& \mathrm{D}$ represented by gross R\&D expenditure (see Note 1).

$I_{\mathrm{g}}=I+J \approx \frac{R_{\mathrm{i}}}{\rho_{i}+g_{\mathrm{i}}}+\frac{R_{\mathrm{j}}}{\rho_{\mathrm{j}}+g_{\mathrm{j}}} \approx \frac{R_{\mathrm{i}}}{\rho+g}+\frac{R_{\mathrm{j}}}{\rho+g}=\frac{R_{\mathrm{i}}+R_{\mathrm{j}}}{\rho+g}=\frac{R}{\rho+g}$

where $R_{\mathrm{j}}: \mathrm{R} \& \mathrm{D}$ related to the Internet, and $R_{\mathrm{i}}$ : R\&D related to other ICT; $\rho$ : rate of obsolescence of ICT, and $g: R \& D$ growth rate at initial stage.

\section{Note 1 ICT stock at time $t$}

ICT stock can be appropriated proportional to gross R\&D:

$$
I_{t}=R_{t-m}+(1-\rho) T_{t-1} \text { and } I_{0}=\frac{R_{1-m}}{\rho+g}
$$

Therefore, $I_{t}=\frac{R_{t+1-m}}{\rho+g}$, when $t \gg m-1, I_{t} \approx \frac{R_{t}}{\rho+g}$

where $m$ : time-lag between R\&D and commercialization.

Substituting equation (5) for $I g$ in equation (4):

$$
\ln V=\alpha+\beta \ln \frac{R}{\rho+g}=\alpha-\beta \ln (\rho+g)+\beta \ln R \equiv \alpha^{\prime}+\beta \ln R
$$

where $\alpha^{\prime}=\alpha-\beta \ln (\rho+g)$.

Thus, digital value is governed by gross $\mathrm{R} \& \mathrm{D}$ in an IoT society.

Given the logistic growth nature of ICT, $V$ can be developed by an $R$-driven logistic growth function.

$$
V \approx F(R), \frac{d V}{d R}=\frac{\partial V}{\partial R} \cdot \frac{d R}{d R}=\frac{\partial V}{\partial R}=a V\left(1-\frac{V}{N}\right)
$$

where $N$ : carrying capacity; and $a$ : velocity of diffusion.

Equation (7) develops the following simple logistic growth function (SLG):

$$
V_{\mathrm{s}}(R)=\frac{N}{1+b e^{-a R}}
$$

where $b$ : coefficient indicating the initial level of diffusion.

This function leads to bipolarization as follows:

$$
\begin{aligned}
b e^{-a R} \equiv & \frac{1}{x} \\
\frac{\partial V}{\partial R} & =a V\left(1-\frac{V}{N}\right)=a N \cdot \frac{1}{1+1 / x}\left(1-\frac{1}{1+1 / x}\right)=\frac{a N \cdot x}{(1+x)^{2}} \\
\frac{d \frac{\partial V}{\partial R}}{d x} & =\frac{d \frac{\partial V}{\partial R}}{d R} \cdot \frac{d R}{d x}=\frac{d \frac{\partial V}{\partial R}}{d R} \cdot \frac{1}{a x}=a N \cdot \frac{1-x}{(1+x)^{3}} \\
\frac{1}{a x} & =\frac{b}{a} e^{-a R}>0
\end{aligned}
$$

Digitalization exceeding certain $\mathrm{R} \& \mathrm{D}$ level $(R>\ln b / a)$ results in productivity decline. 
$\frac{d \frac{\partial V}{\partial R}}{d R}=0 \Leftrightarrow x=1 \Leftrightarrow R=\frac{\ln b}{a} \rightarrow R>\frac{\ln b}{a} \Rightarrow \frac{d \frac{\partial V}{\partial R}}{d x}<0$

Thus, $\frac{\ln b}{a}$ indicates inflection point in $S L G$ (see Note 2).

\section{(2) Self-propagating Function}

Confronting such circumstances, ICT-advanced economies endeavor to transform their business model.

As far as the development trajectory depends on the simple logistic growth $(S L G)$ trajectory, its digital value, $V_{s}(R)$, saturates with the fixed upper limit. However, once the trajectory shifts to logistic growth within the dynamic carrying capacity (LGDCC) trajectory that incorporates the self-propagating function, enhancing the upper limit dynamically as growth proceeds, its digital value, $V_{L}(R)$, can continue to increase, supported by this function.

Recalling particular innovation, which creates new carrying capacity during the process of diffusion, transforming endeavors in response to the foregoing dilemma corresponds to shifting to a $L G D C C$ trajectory (see the details of the mathematical demonstration in the column 2).

Table 3 analyzes the development trajectories of 500 global ICT firms in 2016 by comparing the $S L G$ and $L G D C C$.

Table 3 The Development Trajectory of 500 Global ICT Firms (1996)

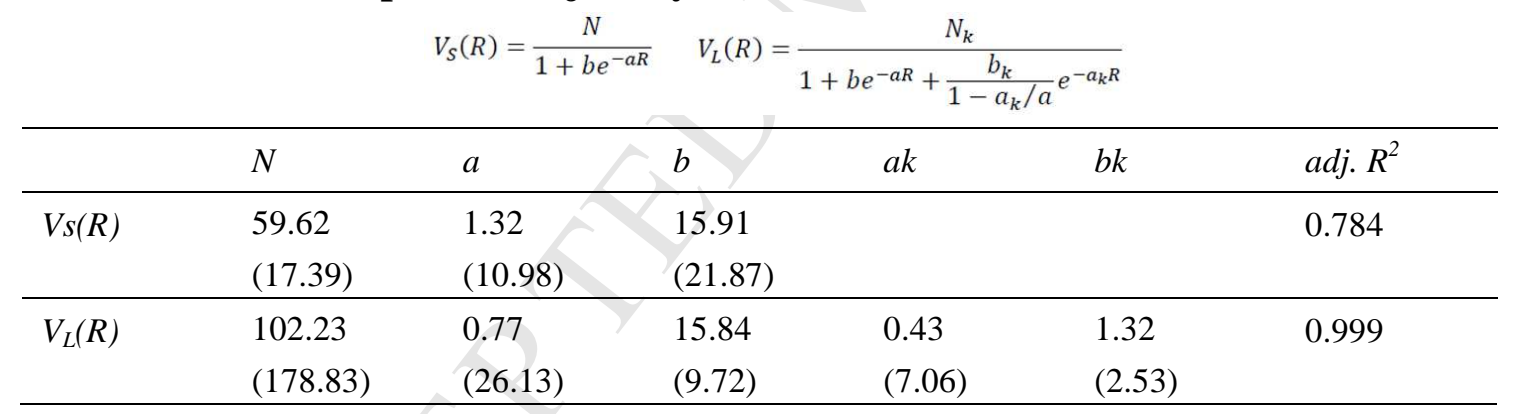

$V_{S}(R), V_{L}(R)$ : the digital value of $S L G$ and $L G D C C$, respectively; $N$ : carrying capacity; $R$ : R\&D expenditure; and $a, b$, $a_{k}, b_{k}$ : coefficients.

Dummy variables are used for $V_{S}(R)$ estimate.

The figures in parentheses indicate t-statistics; all are significant at the $1 \%$ level.

Table 3 demonstrates that $L G D C C$ is statistically more significant than $S L G$. This can be attributed to HRIFs' endeavor to overcome the tradeoff by shifting from $S L G$ to $L G D C C$. This endeavor corresponds to their efforts in arousing and activating the latent self-propagating function incorporated in ICT.

\section{Column 2: Mathematical demonstration}

In particular innovation which creates new carrying capacity $N(R)$ during the process of diffusion, equation (7) is developed as follows:

$$
\frac{d V(R)}{d R}=a V(R)\left(1-\frac{V(R)}{N(R)}\right)
$$

Equation (12) develops the following logistic growth within a dynamic carrying capacity 
function $(L G D C C)$ which incorporates self-propagating function as carrying capacity increases corresponding to $V(R)$ increase as depicted in equation (14) (Watanabe et al., 2004):

$$
\begin{aligned}
& V_{L}(R)=\frac{N_{k}}{1+b e^{-a R}+\frac{b_{k}}{1-a_{k} / a} e^{-a_{k} R}} \\
& N_{L}(R)=V_{L}(R)\left(\frac{1}{1-\frac{1}{a} \cdot \frac{\Delta V_{L}(R)}{V_{L}(R)}}\right) \quad \Delta V_{L}(R)=\frac{d V_{L}(R)}{d R}
\end{aligned}
$$

Induced by this self-propagating function, functionality $(F D)$ spirally increases corresponding to $V(R)$ increase as depicted in equation (15):

$$
F D=\frac{N_{L}(R)}{V_{L}(R)}=\frac{1}{1-\frac{1}{a} \cdot \frac{\Delta V_{L}(R)}{V_{L}(R)}}
$$

As far as the development trajectory depends on $S L G$ trajectory, its digital value $\left(V_{S}(R)\right)$ saturates with upper limit depicted by fixed $N$ without self-propagating function, once the trajectory shifts to $L G D C C$, it can continue to increase supported by self-propagating function and led by dynamically enhancing upper limit $N_{L}(R)$.

Therefore, the magnitude of self-propagating function $(M S P F)$ can be estimated by the ratio of $N_{L}(R)$ and $V_{S}(R)$ as follows (Watanabe et al., 2017b):

$$
M S P F=\frac{N_{L}(R)}{V_{S}(R)}=\frac{V_{L}(R)}{V_{S}(R)} \cdot\left(\frac{1}{1-\frac{1}{a} \cdot \frac{\Delta V_{L}(R)}{V_{L}(R)}}\right)
$$

\section{Note 2 Inflection point in $L G D C C$}

$L G D C C$ function by equation (13) can be approximated by the following $S L G$ function (Watanabe et al., 2009)

$$
\begin{aligned}
& V_{L}(R)=\frac{N_{k}}{1+b e^{-a R}+\frac{b_{k}}{1-a_{k} / a} e^{-a_{k} R}} \approx \frac{N_{k}}{1+b^{\prime e^{-a^{\prime} R}}} \\
& a^{\prime}=a\left(1-\frac{b_{k}}{b}\right), b^{\prime}=b\left(1+\frac{b_{k}}{b} \cdot \frac{1}{1-\frac{a_{k}}{a}}\right) \quad b^{e^{-a^{\prime} R}} \equiv \frac{1}{x} \\
& \frac{\partial V_{L}}{\partial R}=a^{\prime N_{k}} \frac{x}{(1+x)^{2}}, \frac{d \frac{\partial V_{L}}{d x}}{d x}=\frac{d \frac{\partial V_{L}}{d R}}{d R} \cdot \frac{1}{a^{\prime} x}=a^{\prime} N_{k} \cdot \frac{(1-x)}{(1+x)^{3}} \\
& \frac{d \frac{\partial V_{L}}{d R}}{d R}=0 \text { when } x=1\left(R=\frac{\ln b^{\prime}}{a^{\prime}}\right)
\end{aligned}
$$

Therefore, $\frac{d \frac{\partial V_{L}}{\partial R}}{d R}<0$

$$
\text { when } R>\frac{\ln b^{\prime}}{a^{\prime}} \approx \frac{\ln b\left(1+\frac{b_{k} \cdot \frac{1}{b}+\frac{a_{k}}{a}}{\left.1-\frac{b_{k}}{b}\right)}\right.}{a\left(1-\frac{b_{k}}{b}\right)}>\frac{\ln b}{a}
$$

Inflection level in $L G D C C$ is higher than that of in $S L G$ function without self-propagating function.

\section{Note 3 Assessment of self-propagating function}

As reviewed in Section 2.2, ICT incorporates self-propagating potential. This potential can be measured by equation (14) which is governed by the growth rate and the level of development trajectory $\left(V_{L}(R)\right)$. This level in $L G D C C$ is identified by the third term of the denominator of equation (13). This term constitutes $S L G$ function in which a coefficient $a_{k}$ plays a significant role in determining the initial level and velocity of this function. 


\subsection{The Transformative Direction Initiated by Global ICT Leaders}

Based on these analyses, Fig. 9 illustrates the dynamism of HRIFs in 2016 in transforming the productivity decline into supra-functionality beyond economic value that satisfies people's preferences in the digital economy (McDonagh, 2008; Watanabe et al., 2015a; see Appendix 2).

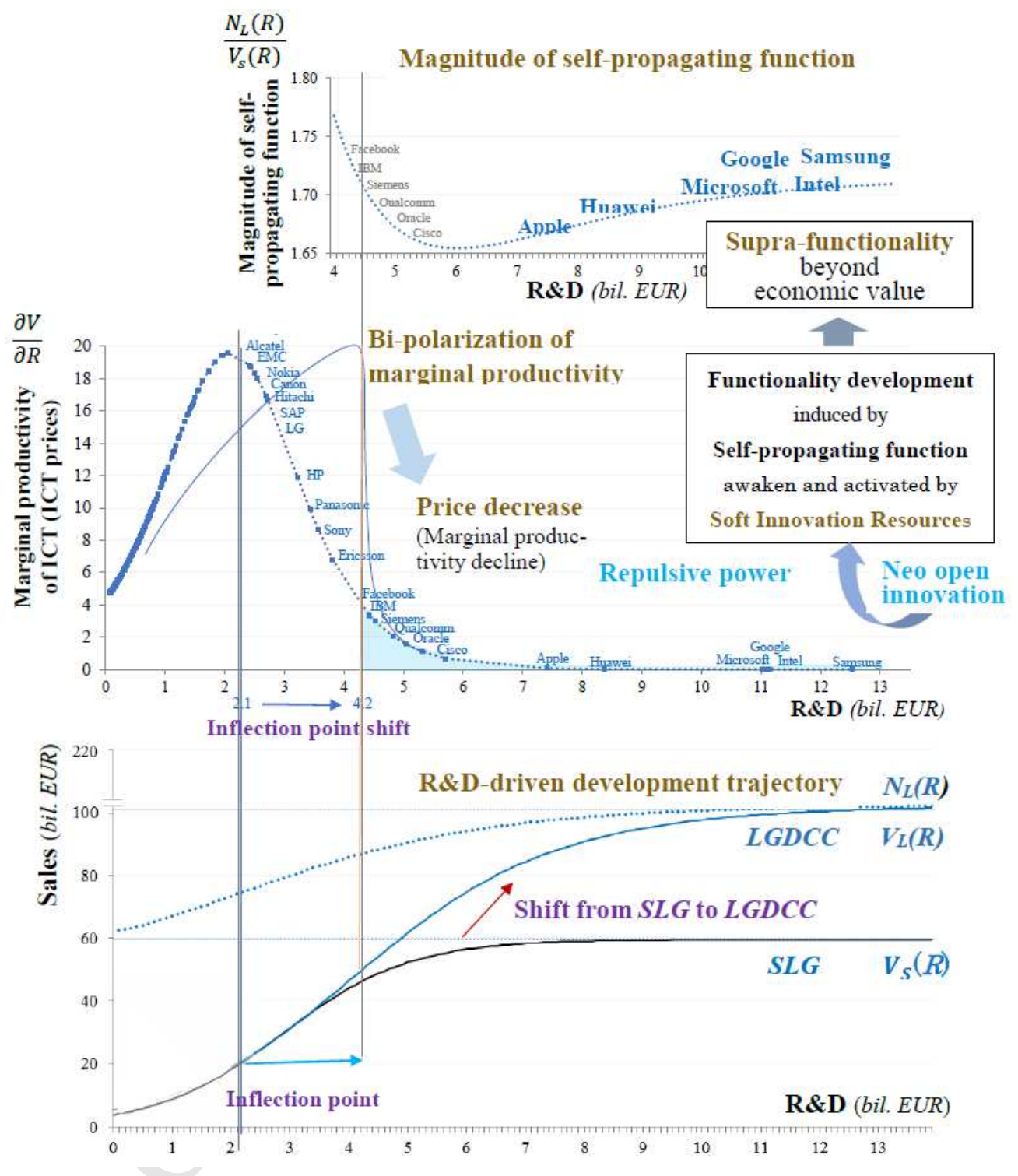

Fig. 9. Dynamism in Transforming the Productivity Decline into Supra-functionality beyond Economic Value in HRIFs (2016).

$V_{S}(R)$ : Digital value in $S L G, V_{L}(\mathrm{R})$ : Digital value in $L G D C C, N_{L}(R)$ : Dynamic carrying capacity in $L G D C C$.

Sources: Developed based on Naveed et al. (2018) and Watanabe et al. (2018b).

The bottom of Fig. 9 demonstrates the R\&D-driven development trajectory of the 500 global ICT firms in 2016. This trajectory shifted from $S L G$ to $L G D C C$ by activating the latent self-propagating function as $R \& D$ investment increased. This could be a countermeasure against the dilemma, the marginal productivity of ICT decline once 
exceeding a certain R\&D investment level (the inflection level), as demonstrated in the middle of Fig. 9.

This inflection level in $L G D C C$ is much higher than that of in $S L G$, without the self-propagating function, which implies that global ICT firms can avoid the productivity decline to some extent by attempting to increase the self-propagating function, as illustrated in the middle-left of Fig. 9 (see the details of this mechanism in Notes 2 and 3 of the column in Section 3.2). However, there exists a certain limit to maintaining the productivity increase by only such an effort. Thus, the excessive dependence on R\&D (proportional to ICT that incorporates a two-faced nature of price formation) necessitates the effective utilization of external resources (e.g., the vigor of $L R I F s$ that enjoy a virtuous cycle between $R$ and $M P$ and/or the external resources that do not accelerate a vicious cycle) to compensate for the productivity decline, as reviewed in Section 2.

Fig. 9 shows that, in repulsion of the marginal productivity of ICT decline, the self-propagating function increases in extremely high R\&D-intensive global ICT firms, such as Samsung, Intel, Google, Microsoft, Huawei and Apple, as demonstrated in the top right of Fig. 9, with their high level of magnitude of the self-propagating function. Thereby, these firms correspond to people's preferences shift to supra-functionality beyond economic value (McDonagh, 2008; Watanabe et al., 2015a).

\subsection{Transformation into a Disruptive Business Model}

\section{(1) The Disruptive Business Model Initiated by Global ICT Leaders}

The above analyses demonstrate the new disruptive business model initiated by the global ICT leaders for increasing functionality development by exploring and utilizing external resources that arouse and activate the latent self-propagating function indigenous to ICT. The activated self-propagating function induces functionality development, leading to supra-functionality beyond economic value that corresponds to people's preferences shift. This shift, in turn, induces the further advancement of the Internet and leverages the co-evolutionary advancement of innovation in the digital economy, as illustrated in Fig. 10.

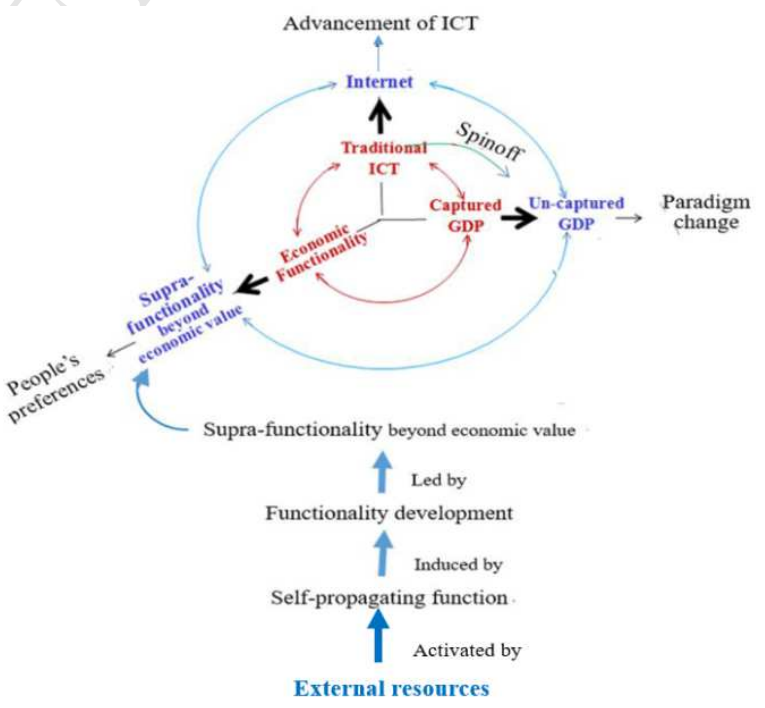


Fig. 10. The Disruptive Business Model Initiated by Global ICT Leaders.

As postulated in Section 2, these external resources could be an incorporation of the vigor of LRIFs that enjoy a virtuous cycle between $R$ and $M P$ and/or of external innovation resources that do not accelerate a vicious cycle.

Harnessing the vigor of emerging and developing countries that not only enjoy the benefit of digital innovation simultaneously with countries of advanced economies but that also demonstrate a leapfrogging accomplishment in the IoT society should be considered as a promising solution to the former option.

However, as reviewed in Section 2, considering the rising capital intensity in ICT-advanced economies and the subsequent increasing burden of such investment (The Economist, 2018), the latter option has become more promising.

\section{(2) Neo Open Innovation by Harnessing Soft Innovation Resources}

Neo open innovation that harnesses the vigor of soft innovation resources that correspond to the digital economy has, thus, become a promising solution to the critical dilemma.

Fig. 11 illustrates the concept of this neo open innovation in the digital economy.

\section{Traditional open innovation}

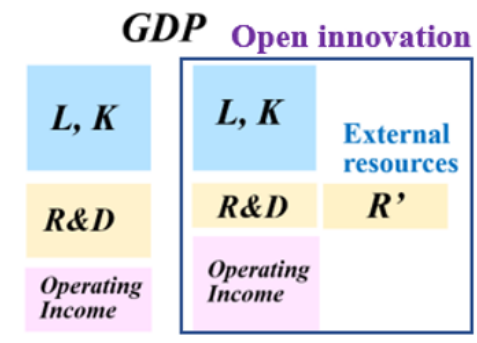

$\boldsymbol{L}$ : labor, $\boldsymbol{K}$ : capital, $\boldsymbol{R}$ : R\&D investment, $\boldsymbol{M P}$ : marginal productivity of ICT, $S I R$ : soft innovation resources

\section{Neo open innovation}

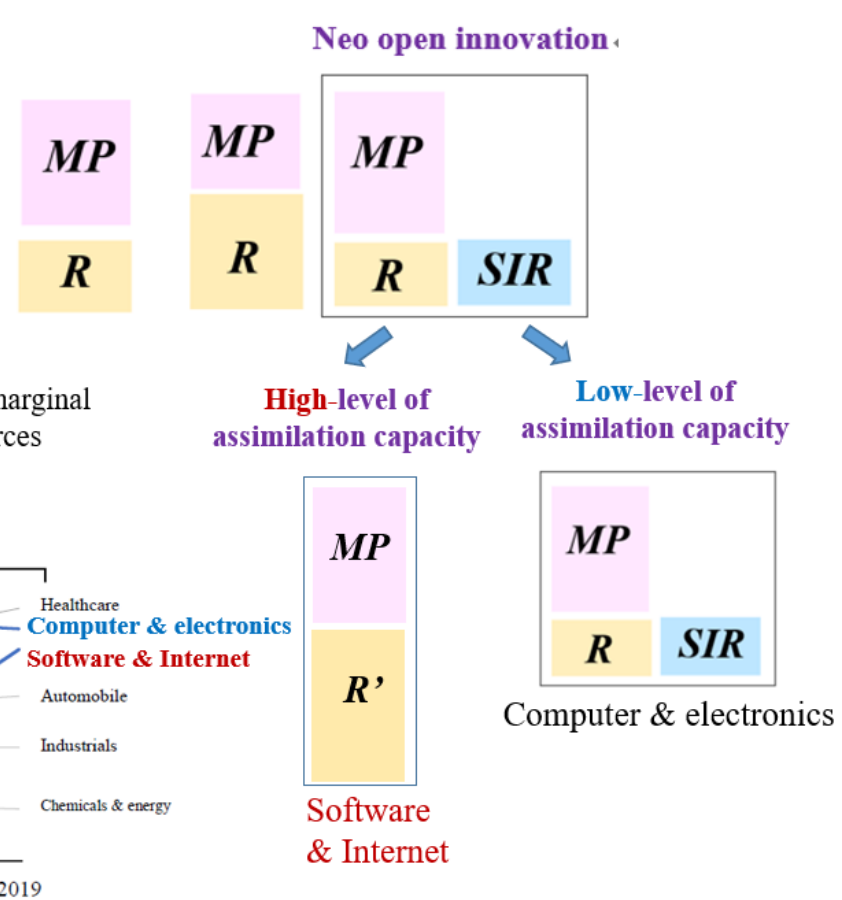

R\&D expenditure in world top 1000 firms (2009-2019).

\section{Fig. 11. The Concept of Neo Open Innovation.}

Source of R\&D expenditure: Bloom berg, 2017 Global Innovation 1000 Study (2017).

Similar to traditional open innovation (Chesbrugh, 2003), soft innovation resources (which are identical to the digital economy and play functions similar to R\&D investment while being external to it) are utilized by absorbing them from the external 
environment and assimilating them into their own system: thereby sustainable growth can be maintained without depending on R\&D investment increases.

\subsection{Soft Innovation Resources in the Global ICT Leaders}

Confronting the foregoing dilemma between $R \& D$ expansion and marginal productivity of ICT decline, HRIFs have been endeavoring to transform into a new business model that creates supra-functionality by harnessing the vigor of soft innovation resources, which arouse and activate the latent self-propagating function, as demonstrated in Fig. 12.

\begin{tabular}{|c|c|c|}
\hline \multicolumn{2}{|c|}{$\begin{array}{c}\text { Transformative direction of ICT-driven } \\
\text { disruptive business model }\end{array}$} & $\begin{array}{l}\text { Soft innovation } \\
\text { resources }\end{array}$ \\
\hline Samsung & $\begin{array}{l}\text { User experiences through } \\
\text { smart design and technology }\end{array}$ & $\begin{array}{l}\text { Supra-functionality } \\
\text { beyond economic value }\end{array}$ \\
\hline Intel & $\begin{array}{l}\text { Empowering the technologies } \\
\text { of the future dream }\end{array}$ & $\begin{array}{l}\text { leeping capable } \\
\text { esources }\end{array}$ \\
\hline Google & $\begin{array}{l}\text { Enabling overdrawing of } \\
\text { information through search }\end{array}$ & $\begin{array}{l}\text { Trust by overdrawing } \\
\text { past information }\end{array}$ \\
\hline Microsoft & $\begin{array}{l}\text { Harnessing the utmost } \\
\text { gratification of consumer delight }\end{array}$ & $\begin{array}{l}\text { Utmost gratification } \\
\text { ever experienced }\end{array}$ \\
\hline Huawei & $\begin{array}{l}\text { Building a better-connected } \\
\text { world }\end{array}$ & emory and future \\
\hline Apple & $\begin{array}{l}\text { Personalized user experiences } \\
\text { through top-quality products }\end{array}$ & \\
\hline Amazon & Fusing net and real & \\
\hline
\end{tabular}

Fig. 12. The Transformative Direction of HRIFs in Response to Productivity Decline in the Digital Economy.

Source: Naveed et al. (2018).

It is claimed that the use of soft innovation resources is a novel innovation mode, initiated by the forefront of HRIFs as a constructive solution to the dilemma between $\mathrm{R} \& \mathrm{D}$ increase and productivity decline. Authors in previous studies described this hypothetical view (Watanabe et al., 2015a) and demonstrated that while the digital economy results in a productivity decline, highly R\&D-intensive global ICT firms endeavor to survive through the spontaneous creation of uncaptured GDP by harnessing the vigor of soft innovation resources (Watanabe et al., 2018b).

As demonstrated in Fig. 12, such soft innovation resources consist of the Internet-based (permeating into broad ICT in the digital platform economy) resources that have been sleeping, or untapped, or are the results of multisided interactions in the markets, where the consumer is looking for supra-functionality beyond economic value. Soft innovation resources, thus, are considered condensates and crystals of the Internet. The common

${ }^{4}$ Soft innovation resources substitute for additional R\&D investment that may decline marginal productivity and induce production factors, contributing to production growth (see the detailed mechanism in Section 5.2). 
feature of soft innovation resources is that contrary to their contribution, leading to supra-functionality, they are not accountable in the traditional GDP terms (Watanabe et al., 2018c).

Thus, the absorption and assimilation of soft innovation resources can be counted as contributors to growth but not counted as additional expenditures, as suggested in Fig. 11 .

\section{The Hybrid Role of Soft Innovation Resources}

\subsection{Dynamism in Performing the Hybrid Function}

Soft innovation resources arouse and activate the latent self-propagating function indigenous to ICT, which induces functionality development, leading to supra-functionality beyond economic value. This corresponds to people's preferences shift and induces further advancement of the Internet. Furthermore, this advancement accelerates the increasing dependence on uncaptured GDP, which leverages the harnessing of the vigor of soft innovation resources, as reviewed earlier. At the same time, the advancement of the Internet arouses and induces soft innovation resources, as they are a crystal of the Internet. Thus, a virtuous cycle exists between the emergence and utilization of soft innovation resources, supra-functionality beyond economic value, advancement of the Internet, uncaptured GDP dependence, and further leverage to soft innovation resources emergence, as illustrated in Fig. 1.

In addition, it cannot be overlooked that soft innovation resources also contribute to captured GDP increases by removing the structural impediments to its growth. An example of this can be observed in Finland's recent resurgence in GDP growth (Tou et al., 2018a, 2018b).

While Finland and Singapore have been maintaining world digital leader positions (WEF, 2017), both countries have demonstrated an interlaced contrast. Finland has enjoyed a high level of happiness/welfare under the stagnation while Singapore has accomplished higher economic growth in the lower level of happiness/welfare (Watanabe et al., 2018c, 2018d). This observation reinforces a plausible view that the "well-being of the Finnish people has developed in a more positive direction than one might conclude by GDP data" (Ylhainen, 2017); furthermore, it prompts the hypothetical view that Finland has depended on uncaptured GDP more largely than Singapore by spinning-off from the traditional co-evolution of economic value, traditional ICT development, and GDP growth into a new co-evolution of people's preferences shifting towards supra-functionality beyond economic value (encompassing social, cultural, and emotional values), advancement of the Internet for further functionality, and increasing dependence on uncaptured GDP, as illustrated in Fig. 1 (Watanabe et al., 2015b).

However, the recent reversal trend in GDP growth between the two digital leaders (Finland's resurgence and Singapore's stagnation during a reversal in R\&D dependence) reveals that Finland's resurgence can be attributed to soft innovation resources that function by removing structural impediments in growth. Soft innovation resources act to remove structural impediments of GDP growth, such as conflict between the public, employers, and labor unions, gender disparity, and increasing discrepancy concerning an aging society (Tou et al., 2018a). 
Thus, the spontaneous creation of uncaptured GDP through the effective utilization of soft innovation resources contributes to growth through its hybrid function, as illustrated in Fig. 1 (Watanabe et al., 2018b).

\subsection{Assessment of Soft Innovation Resources as a Crystal of the Internet}

Based on the augmented permeation of the Internet into broad ICT and the subsequent creation of a new social ecosystem, particularly with smartphones, as reviewed in Section 2, the innovation dynamism in the IoT society that has been activated by soft innovation resources can be described as follows:

(i) Since global ICT firms are at the forefront of the IoT society, soft innovation resources, especially their critical resources against productivity decline in the digital economy, seem to be a condensate and crystal of the Internet/smartphones.

(ii) Soft innovation resources arouse and activate a latent self-propagating function indigenous to ICT, which can be attributed to the Internet permeating into soft innovation resources.

(iii) The activated self-propagating function induces functionality development, which leads to supra-functionality beyond economic value, corresponding to a shift in people's preferences. This shift, in turn, induces further advancement of the Internet.

Based on these three postulates, the assessment of the conceptualization and operationalization of soft innovation resources can be undertaken through the three approaches, as illustrated in Fig. 13.

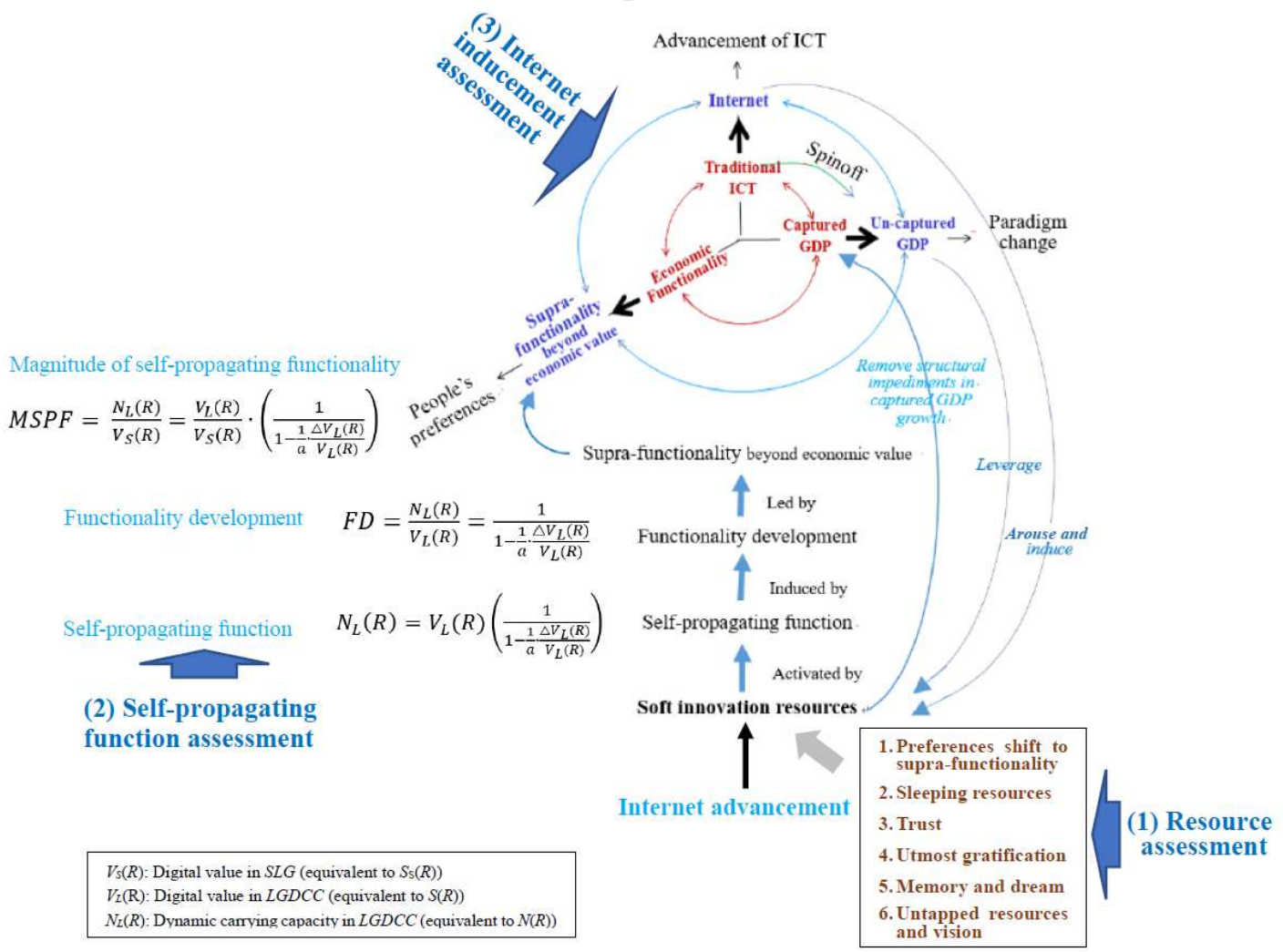

Fig. 13. Three Approaches for the Conceptualization and Operationalization of Soft Innovation Resources. 


\section{(1) Resources Assessment}

First, considering typical soft innovation resources, the correlation with the advancement of the Internet/smartphones was examined.

\section{1) Sleeping Resources}

Following the preceding analysis on "Uber's Ride-sharing Revolution" (Watanabe et al., $2016 b, 2017 a$ ), the effect of the advancement of the Internet on Uber's increase was examined. Given the close relationship between the Internet and smartphone dependence, as demonstrated in 2.1 (3), a monthly trend in smartphone dependence was used. Summarized in Table 4, the results of analysis were statistically significant and demonstrated that the advancement of the Internet (via smartphone) significantly contributed to the utilization of sleeping resources by reducing prices typically observed with Uber.

Table 4 The Correlation between Smartphones and Uber in New York (Jun. 2013 - Sep. 2015)

$$
\begin{array}{ccccc}
\ln U_{p}= & 12.07-2.17 D_{1} \ln S P-2.16 D_{2} \ln S P-0.16 D & \text { adj. } R^{2} & 0.954 \\
(19.07)(-14.40) & (-14.72) & (-6.25) & D W & 1.03
\end{array}
$$

$U_{p}$ : Price of Uber (US\$/trip); SP: Smartphone share in the US telephone market (\%).

$D$ : Dummy variables; $D_{1}$ : Jun. 2013 - Oct. $2014=1$, others = 0; $D_{2}$ : Nov. 2014 - Sep. $2015=1$, others = 0; $D$ : Jun. 2015 - Sep. $2015=1$. others $=0$.

The figures in parentheses indicate the t-statistics: all are significant at the $1 \%$ level except ${ }^{*} 5 \%,{ }^{* *} 10 \%$ (same as following analyses).

\section{2) Trust}

Following the preceding analysis of the "Co-evolution between trust in teachers and higher education toward digital-rich learning environments" (Watanabe et al., 2016c), the effects of the advancement of the Internet on an increase in trust were examined. Summarized in Table 5, the results of the analysis were statistically significant and demonstrated that the advancement of the Internet contributed to an increase in trust in 12 ICT advanced countries.

Table 5 The Correlation between Internet Dependence and Trust in 20 Countries (2013)

$$
\begin{array}{rrrrr}
\ln X= & \begin{array}{r}
2.59+0.32 \\
(4.94)
\end{array} D_{1} \ln I D-0.18 D_{2} \ln I D-2.14 D_{1}-0.16 D_{\alpha}+0.10 D_{\beta} & \text { adj. } R^{2} 0.734 \\
(-1.35)^{* *} & (-2.20)^{*} & (-5.25) & (2.28) &
\end{array}
$$

$X$ : Level of trust in teachers to deliver a good education; $I D$ : Internet dependence; $D$ : Dummy variables

$D_{1}$ : Israel, Czech, Singapore, France, New Zealand, Germany, Korea, Switzerland, Japan, UK, Finland, Netherland $=1$, others $=0$

$D_{2}$ : China, Turkey, Brazil, Italy, Greese, Portugal, USA, Spain $=1$, others $=0$

$D_{\alpha}:$ Korea, Japan $=1$. others $=0 \quad D_{\beta}:$ USA, Spain $=1$, others $=0$

\section{3) Memory and Dream}

Following the preceding analysis on the "Co-evolution between streaming and live music" (Naveed et al., 2017), the effect of the advancement of the Internet on the reactivation of live music was examined. Similar to Uber, monthly trends in smartphone dependence were used. Summarized in Table 6, the results of the analysis were statistically significant and demonstrated that the advancement of the Internet (via 
smartphones) significantly contributed to reactivation of live music.

Table 6 The Correlation between Smartphones and Live Music in the US (Jun. 2013 Sep. 2015)
$\ln L M=1.34+1.13 \ln S P-0.02 D_{1}+0.02 D_{2} \quad$ adj. $R^{2} 0.996$
(21.67) (77.85) (-2.46) (4.09) DW 1.25

LM: Revenue of live music (mil. US\$); SP: Smartphone share in the US telephone market (\%).

$D$ : Dummy variables; $D_{1}$ : Feb. $2014=1$, others $=0 ; D_{2}$ : Sep. 2014 - Nov. $2014=1$, others $=0$

\section{4) Untapped Resources}

Following the preceding analysis on "Harnessing women's potential as untapped resources" (Watanabe et al., 2017b), the effects of the advancement of the Internet on the utilization of untapped resources were examined. Summarized in Table 7, the results of the analysis were statistically significant and demonstrated that the advancement of the Internet contributed to gender balance improvement.

Table 7 The Correlation between Internet Dependence, Gender Balance Improvement and Male-dominated Society in 44 Countries (2013)

$$
\begin{aligned}
& \ln Y=0.99+0.30 D_{1} \ln I D+0.40 D_{2} \ln I D+0.36 D_{3} \ln I D \\
& (1.46)^{* *}(1.63)^{* *} \quad(2.63) \quad(2.16) \\
& -0.31 D_{2} \ln W-2.93 D_{3} \ln W-0.98 D_{a}+0.72 D_{b} \quad \text { adj. } R^{2} 0.801 \\
& \begin{array}{llll}
(-2.60) \quad(-5.58) & (-7.57) \quad(3.12)
\end{array}
\end{aligned}
$$

Y: Gender balance index; ID: Internet dependence; $W$ : Intensity of male dominated society.

$D_{l}, D_{2}$ and $D_{3}$ : Coefficient dummy variables corresponding to EMC (13 emerging countries), INC (27 industrialized countries) and CSC (4 countries with specific culture), respectively.

$D$ : Dummy variable: $D_{a}$ : BEL, CHL, HUN, TWN, RUS, PRT, BRA, GRC, EGY $=1$, others $=0 ; D_{b}$ : NOR, SAU $=1$, others $=0$.

All cases demonstrated that soft innovation resources have been governed significantly by the advancement of the Internet and are considered as a condensate and crystal of the Internet.

\section{(2) Self-propagating Function Assessment}

Next, the second postulate, that "attributed to the advancement of the Internet, soft innovation resources activate a latent self-propagating function", was examined.

Table 8 summarizes the result of the correlation analysis between Internet dependence and the self-propagating function in UPM (a world circular economy leader; Watanabe et al., 2018e). The results were statistically significant and demonstrated that the advancement of the Internet contributed to a significant increase in the self-propagating function. Its contribution increased as Internet dependence increased.

\section{Table 8 The Correlation between Internet Dependence and the Self-propagating Function \\ in UPN (1995-2017)}

$$
\begin{aligned}
& \ln N_{L}(R)=2.973+0.362 D_{1} \ln I D+0.424 D_{2} \ln I D+0.536 D_{3} \ln I D \quad \operatorname{adj} . R^{2} 0.985
\end{aligned}
$$

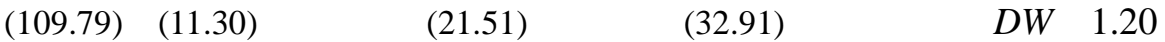


$N_{L}(R)$ : Self-propagating function; $I D$ : Internet dependence; $D$ : Dummy variables

$D_{1:}: 1995-2002=1$, others $=0 ; D_{2}: 2003-2007=1$, others $=0 ; D_{3}: 2008-2017=1$, others $=0$

\section{(3) Internet Inducement Assessment}

Third, inspired by the preceding two demonstrations, the third postulate, that "activated self-propagating function induces functionality development, leading to supra-functionality, which, in turn, induces further advancement of the Internet", was examined.

Table 9 summarizes the correlation between supra-functionality and the advancement of the Internet in Japan, which is sensitive to institutional innovation concerning external shocks and crises.

Table 9 The Correlation between the Preferences Shift and the Advancement of the Internet in Japan (1995-2017)

$$
\begin{aligned}
& \ln J=-35.87+9.08 D_{1} \ln Q+9.64 D_{2} \ln Q+9.77 D_{3} \ln Q \quad \text { adj. } R^{2} \quad 0.890
\end{aligned}
$$

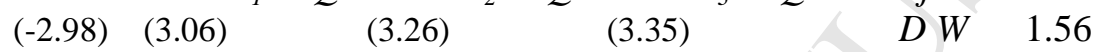

$J$ : Internet dependence; $Q$ : Preference ratio of supra-functionality beyond economic value; $D$ : Dummy variables $\left(D_{1}: 1995-1996=1\right.$, others $=0 ; D_{2}: 1997-2003=1$, others $=0 ; D_{3}: 2004-2017=1$, others $\left.=0\right)$.

Table 9 shows statistical significance and demonstrated that the shift of people's preferences to supra-functionality beyond economic value significantly induced the advancement of the Internet in Japan. This inducement increased as the Internet dependence increased.

All three analyses demonstrated the significant correlation between the advancement of the Internet and soft innovation resources or their subsequent, such as the self-propagating function, and, also, people's preferences shift to supra-functionality beyond economic value.

These results support the supposition that soft innovation resources could be considered as a condensate and crystal of the advancement of the Internet.

Given the co-evolution between these factors in the emerging innovation in the digital economy, as illustrated in Figs. 9 and 11, it is postulated that effective utilization of soft innovation resources would be critical for sustainable growth amidst mega competition in the digital economy. 


\section{The Mechanism of the Hybrid Role of Soft Innovation Resources}

\subsection{The Reversal Trend in ICT Leaders}

\section{(1) The Reversal Trend in GDP Growth Rate}

Fig. 14 compares the trend in the real GDP growth rates of two world digital leaders, Finland and Singapore, over a period from 1980-2018.

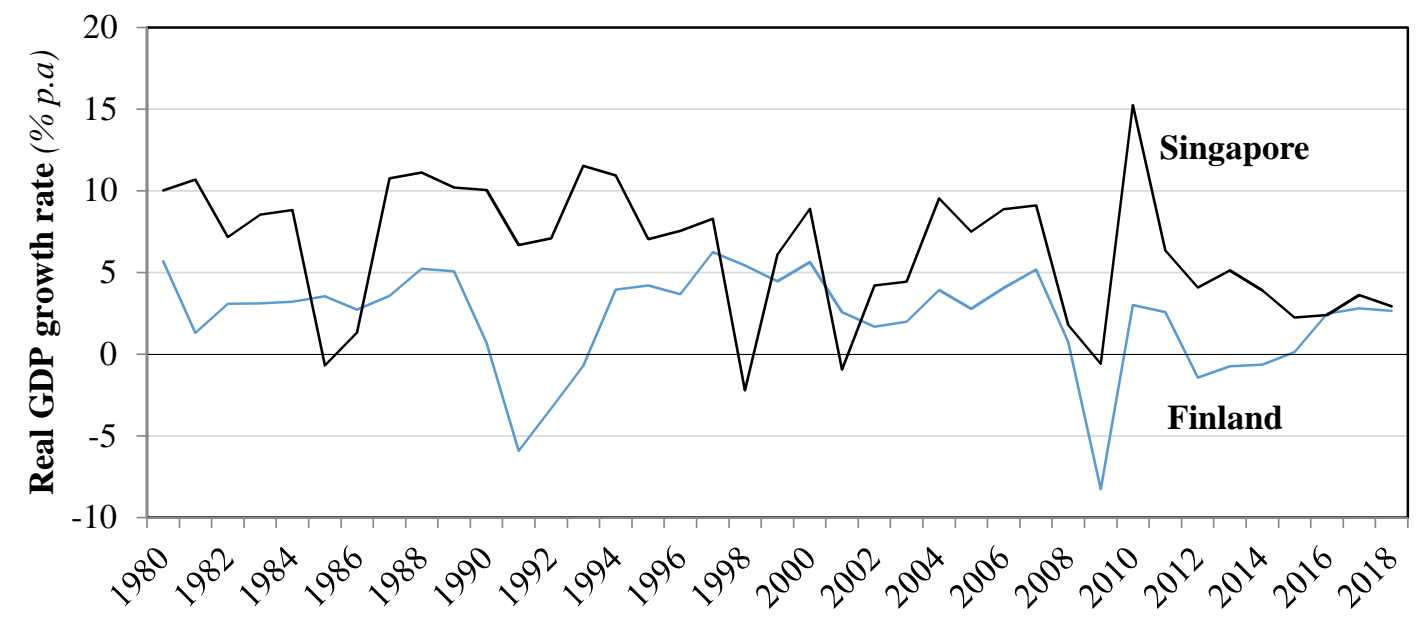

Fig. 14. Trends in the Real GDP Growth Rates of Finland and Singapore (1980-2018).

Source: World Economic Outlook (IMF, October 2018b);

While Singapore exceeded the GDP growth rate of Finland for many years, Finland has been catching up with Singapore's growth rate after 2016 by transforming its long-lasting negative growth into positive growth from 2015 onwards, as demonstrated in Fig. 15.

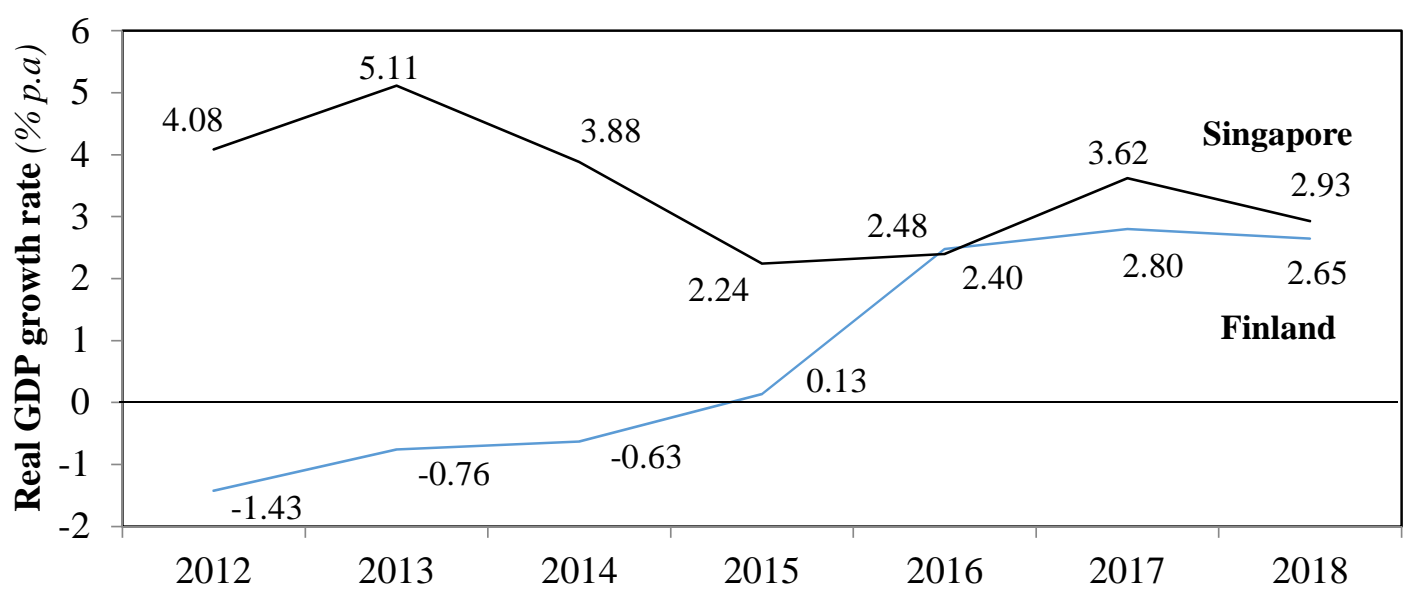

Fig. 15. The Recent Reversal in GDP Growth of Digital Leaders (2012-2018).

Source: Same as Fig. 14. 


\section{(2) Factors Contributing to the Reversal}

Aiming at elucidating the structural source of such a notable closing trend for these two digital leaders in recent years, Table 10 analyzes the contributors to the GDP growth rates in two leaders over the period from 2012-2017.

Table 10 The Trend in GDP Growth Rates and their Composition in Finland and Singapore (2012-2017) - real GDP growth rate (\% p.a)

\begin{tabular}{lcccccc}
\hline Finland & $\mathbf{2 0 1 2}$ & $\mathbf{2 0 1 3}$ & $\mathbf{2 0 1 4}$ & $\mathbf{2 0 1 5}$ & $\mathbf{2 0 1 6}$ & $\mathbf{2 0 1 7}$ \\
\hline Private consumption & 0.14 & -2.24 & 0.06 & 1.48 & 0.93 & 0.99 \\
\hline Government consumption & 0.09 & 2.44 & -0.02 & 0.08 & 0.38 & -0.17 \\
\hline Gross fixed capital & -0.34 & -9.98 & -0.08 & 0.22 & 1.49 & 1.19 \\
\hline $\begin{array}{l}\text { Net exports of goods and } \\
\text { services }\end{array}$ & -0.48 & 8.95 & -0.62 & -1.91 & -0.18 & 0.67 \\
\hline $\begin{array}{l}\text { Others (inventories \& net } \\
\text { acquisitions of variables) }\end{array}$ & -0.85 & 0.07 & 0.02 & 0.27 & -0.14 & 0.13 \\
\hline Total & $\mathbf{- 1 . 4 3}$ & $\mathbf{- 0 . 7 6}$ & $\mathbf{- 0 . 6 3}$ & $\mathbf{0 . 1 4}$ & $\mathbf{2 . 4 8}$ & $\mathbf{2 . 8 0}$ \\
\hline Singapore & $\mathbf{2 0 1 2}$ & $\mathbf{2 0 1 3}$ & $\mathbf{2 0 1 4}$ & $\mathbf{2 0 1 5}$ & $\mathbf{2 0 1 6}$ & $\mathbf{2 0 1 7}$ \\
\hline Private consumption & 1.44 & 1.28 & 1.53 & 1.57 & 0.39 & 1.38 \\
\hline Government consumption & -0.14 & 1.02 & 0.03 & 0.67 & 0.23 & 0.54 \\
\hline Gross fixed capital & 2.20 & 1.69 & 1.87 & 0.54 & -0.10 & -0.58 \\
\hline $\begin{array}{l}\text { Net exports of goods and } \\
\text { services }\end{array}$ & -1.19 & 1.27 & 1.65 & 1.75 & 1.15 & -0.77 \\
\hline $\begin{array}{l}\text { Others (inventories \& net } \\
\text { acquisitions of variables) }\end{array}$ & 1.77 & -0.15 & -1.20 & -2.29 & 0.73 & 3.05 \\
\hline Total & $\mathbf{4 . 0 8}$ & $\mathbf{5 . 1 1}$ & $\mathbf{3 . 8 8}$ & $\mathbf{2 . 2 4}$ & $\mathbf{2 . 4 0}$ & $\mathbf{3 . 6 2}$ \\
\hline Sol & & & & & & \\
\hline
\end{tabular}

Sources: National Accounts of Finland (Statistics of Finland, 2018a); National Accounts of Singapore (Department of Statistics Singapore, 2018).

Looking at Table 10, we note that, contrary to Singapore, Finland's recent GDP growth recovery can largely be attributed to its gross fixed capital formation, to which negative contribution in Singapore.

With such a notable contrasting observation, Fig. 16 compares the trend in the shares of gross service capital (centered on R\&D) out of the gross fixed capital formation in both countries over a period from 2012-2017, as R\&D is assumed to be a driver to such recovery. Fig. 16 reveals that while Singapore demonstrates stable or increasing share, as anticipated, Finland has been shifting to less dependence on gross service capital in 
its gross fixed capital formation, contrary to Singapore's performance.

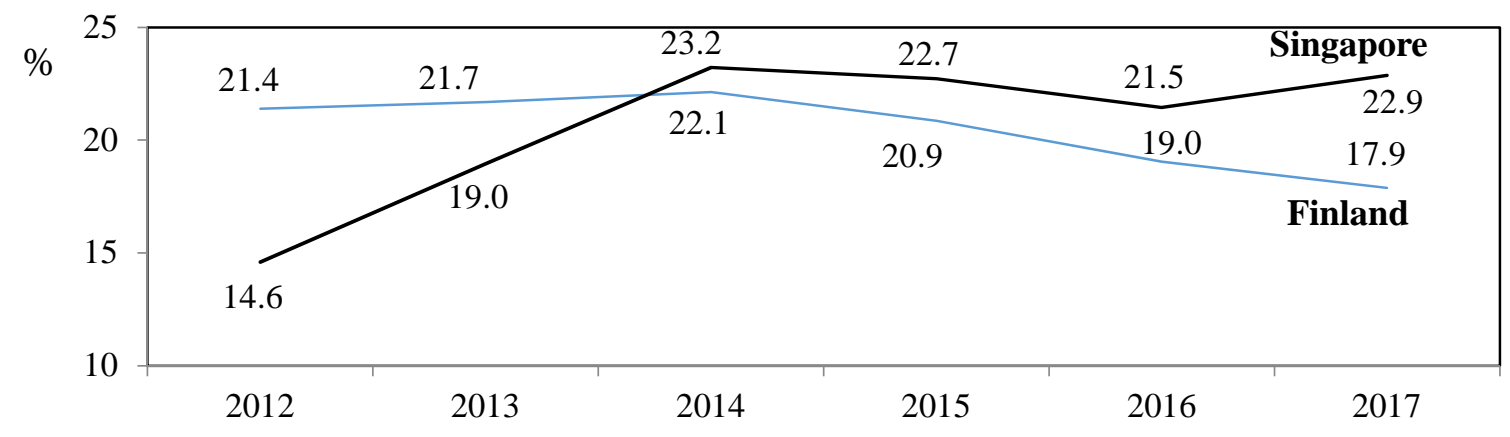

Fig. 16. The Trend in the Share of Gross Service Capital $(\kappa)$ in Finland and Singapore (2012-2017).

In light of the primal contribution of gross fixed capital formation $(G C)$ to the recent notable resurgence of Finland's GDP growth and also the contrasting trend in dependence on gross service capital $(G S C)$ in $G C$ between the two leaders, contributors to $G C$ were analyzed by dividing $G C$ into $G S C$ and gross tangible capital $(G T C)$. Here, $G S C$ is represented by intellectual property products (IPP) in the national accounts, encompassing $\mathrm{R} \& \mathrm{D}$, software and databases, mineral exploration and evaluation, and entertainment, literary or artistic originals. GTC includes tangible assets, such as machinery, vehicles, plant, dwellings, buildings, and land improvements.

Table 11 summarizes the comparison of $G C$ growth contributors in Finland and Singapore over a period from 2012-2017 (see the details of the decomposition analysis in Table A2 in Appendix 1).

Table 11 The Contributions to the Growth Rate of Gross Fixed Capital $(G C)$ in Finland and Singapore (2012-2017) - \%.

\begin{tabular}{lcccccc}
\cline { 2 - 7 } & $\mathbf{2 0 1 2}$ & $\mathbf{2 0 1 3}$ & $\mathbf{2 0 1 4}$ & $\mathbf{2 0 1 5}$ & $\mathbf{2 0 1 6}$ & $\mathbf{2 0 1 7}$ \\
\hline GDP & -1.43 & -0.76 & -0.63 & 0.14 & 2.48 & 2.80 \\
\hline GC contribution to GDP & -0.34 & -9.98 & -0.08 & 0.22 & 1.49 & 1.19 \\
\hline GSC contribution to GDP & -0.83 & -1.89 & 0.44 & -1.24 & -1.53 & -0.94 \\
\hline GTC contribution to GDP & 0.49 & -8.09 & -0.52 & 1.46 & 3.02 & 2.13 \\
\hline GDP & 4.08 & 5.11 & 3.88 & 2.24 & 2.40 & 3.62 \\
\hline GC contribution to GDP & 2.20 & 1.69 & 1.87 & 0.54 & -0.10 & -0.58 \\
\hline GSC contribution to GDP & 0.43 & 4.67 & 4.71 & -0.38 & -1.30 & 1.29 \\
\hline GTC contribution to GDP & 1.77 & -2.98 & -2.84 & 0.92 & 1.20 & -1.87 \\
\hline
\end{tabular}

Sources: Same as Table 10.

Table 11 clearly demonstrates that Finland's $G C$ growth, which is a primal contributor to its GDP recovery, can be attributed to GTC growth while GSC demonstrates negative growth. This contribution of GTC's growth is conspicuous in comparison to similar contributions in Singapore, as demonstrated in Fig. 17. 


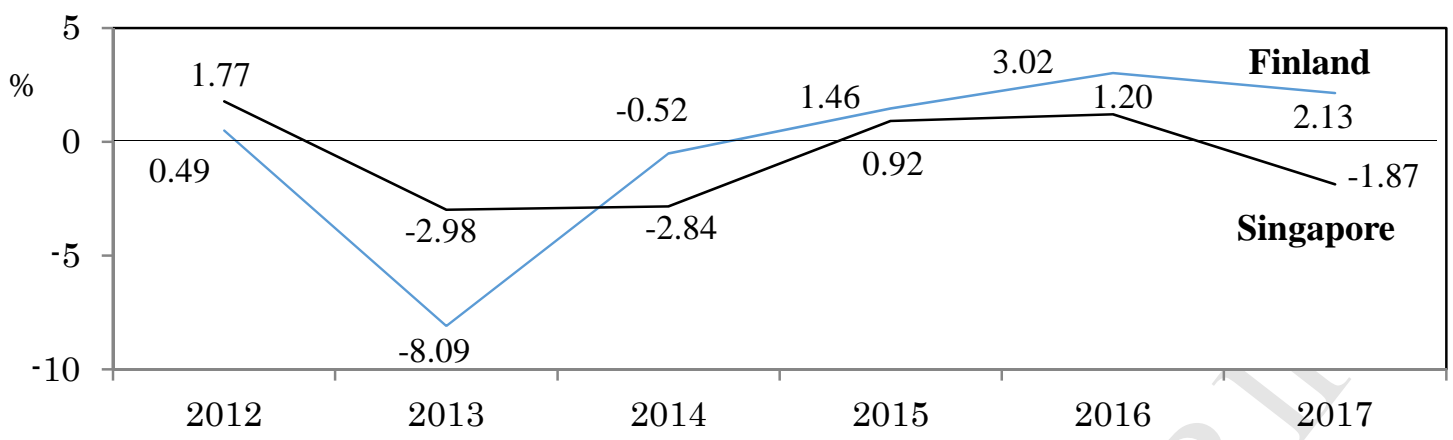

Fig. 17. The Trends in the Gross Tangible Capital $(G T C)$ Contributions to the GDP Growth Rates in Finland and Singapore (2012-2017).

\section{(3) Contrast in R\&D Dependence}

Inspired by the above observation that Finland's recent notable resurgence in GDP growth has depended on GTC's increase while GSC demonstrates a negative increase against anticipation, the trend in the $R \& D$ dependence of the two leaders was reviewed.

Fig. 18 compares the trends in R\&D expenditures between Finland and Singapore over a period from 1995-2016 by decomposing the business enterprise R\&D and government R\&D.
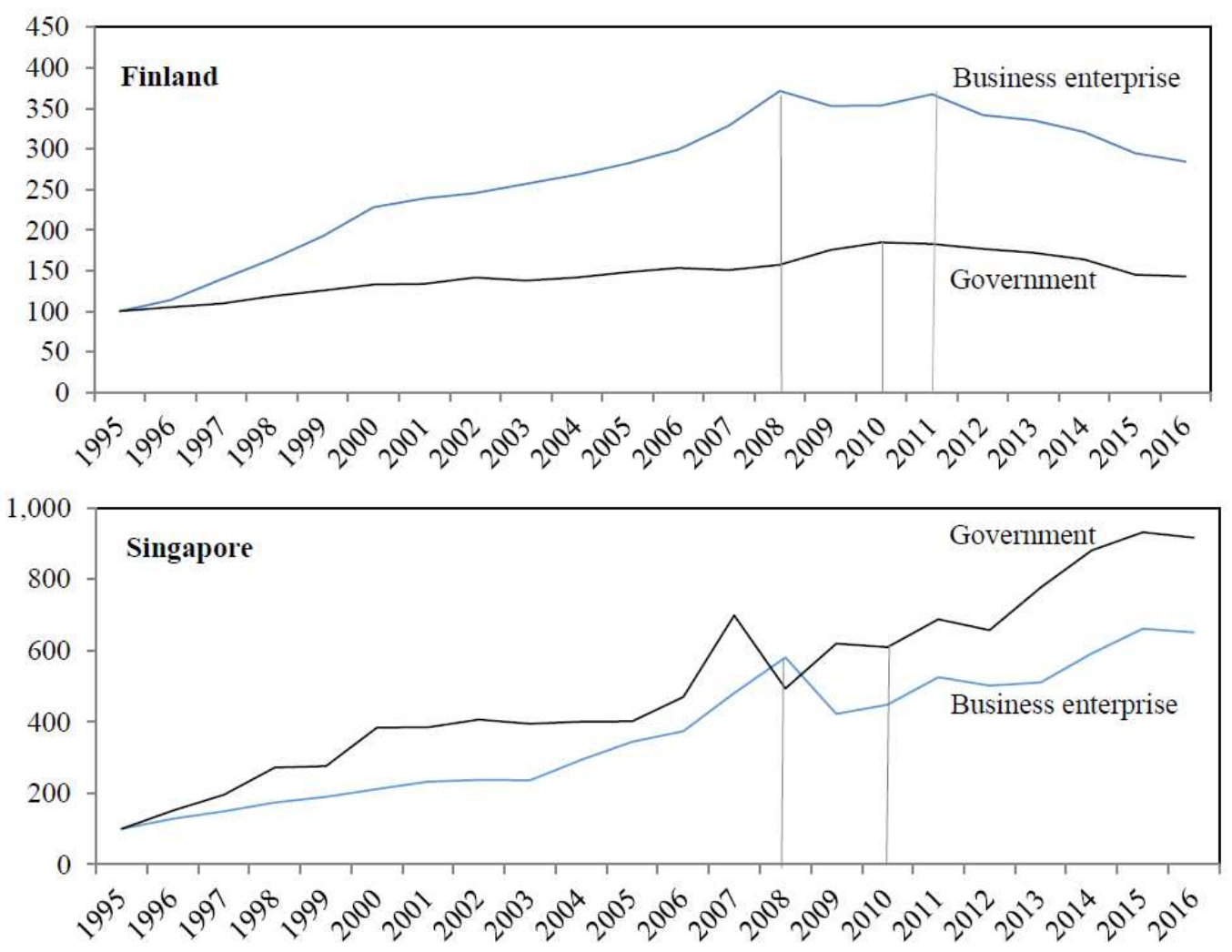

Fig. 18. Trends in R\&D Expenditures by Government and Business in Finland 
and Singapore (1995-2016) - index: $1995=100$.

Sources: Same as Table 10.

Both leaders experienced a sharp decrease in their R\&D investment both in government and business enterprises after the Lehman shock in 2008. However, contrary to Singapore's prompt recovery from 2010 under strong government initiative, Finland suffered longer stagnation both in government and business enterprises.

In Finland, while business-funding R\&D started to decline due to the Lehman shock in 2008, government funding of R\&D continued to grow. However, it switched from an expansionary to a contractionary policy after 2010 , which exacerbated a massive decline in business-funded R\&D (Hutchenreiter et al., 2017).

Consequently, R\&D intensity has shown a decreasing trend in Finland from 2010, as demonstrated in Fig. 19, which compares the trend in R\&D intensity between Finland and Singapore over a period from 1995-2016. This trend also demonstrates the contrast between the two digital leaders after the Lehman shock in 2008. Such a contrast seems to be a consequence of the development trajectory management of the trade-off of R\&D investment and productivity decline, as reviewed in Section 2.

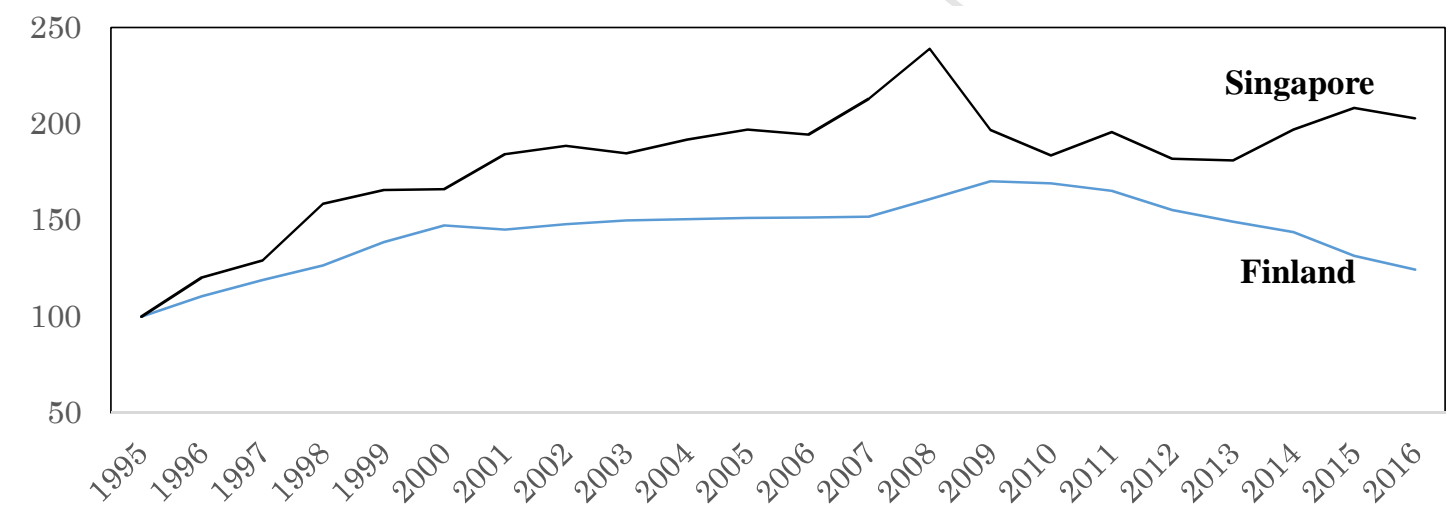

Fig. 19. The Trend in R\&D Intensity in Finland and Singapore (1995-2016) - index: 1995 $=100$.

Sources: Same as Table 10.

Given the increasing burden of ICT R\&D investment (The Economist, 2018), which shares the majority of GSC while its productivity has been declining as a consequence of the two-faced nature of ICT, Finland, based on neo-open innovation, appears to have transformed its trajectory into the utilization of the hybrid role of soft innovation resources, as reviewed in Section 4. Its growth of GTC while depending less on GSC prompts a hypothetical view that given its effective utilization of soft innovation resources, as reviewed in Section 4.1, these resources are substituted for GSC and remove structural impediments to $G T C$ growth, leading to its significant contribution to $G C$ growth, which is a primal contributor to the GDP resurgence in Finland.

The next Section attempts to demonstrate this hypothetical view. 


\subsection{The Dynamism Enabling Finland's Resurgence}

\section{(1) Dynamism}

Analysis in the preceding Section prompted a hypothetical view that soft innovation resources could substitute for $G S C$ that spilled-over to GTC and removed its structural impediments in growth. Fig. 20 illustrates this hypothetical dynamism.
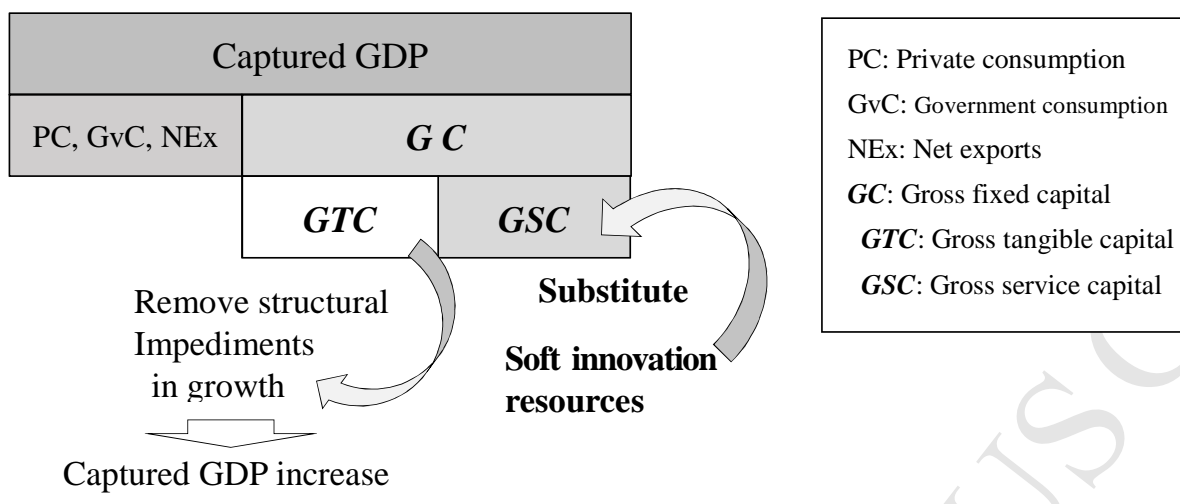

Fig. 20. Dynamism of Finland's Resurgence.

\section{(2) Demonstration}

By means of an empirical analysis of Finland's development trajectory, utilizing its national accounting statistics over a period from 1995-2018, this hypothetical dynamism was demonstrated.

\section{1) Institutional Change in Finland}

Critical institutional change in Finland in the period can be identified in Table 12.

Table 12 Institutional Change in Finland over the last Quarter Century (1995-2018)

\begin{tabular}{lccccc}
\hline D: Dummy variables & $\begin{array}{c}1995- \\
2009\end{array}$ & $\begin{array}{c}2010 \\
-2015\end{array}$ & $\begin{array}{c}2016 \\
-2018\end{array}$ & Features of the period \\
\hline$D_{1} \quad 1995-2009=1$, others $=0$ & 1 & 0 & 0 & $\begin{array}{l}\text { Sustainable increase in R\&D intensity that supported } \\
\text { economic growth. }\end{array}$ \\
\hline$D_{2} \quad 2010-2015=1$, others $=0$ & 0 & 1 & 0 & $\begin{array}{l}\text { Government funding of R\&D switched from expansionary } \\
\text { to contractionary that exacerbated R\&D intensity decline. }\end{array}$ \\
\hline$D_{3} \quad 2016-2018=1$, others $=0$ & 0 & 0 & 1 & $\begin{array}{l}\text { Economic resurgence after the Competitiveness Pact } \\
\text { (June 2016, see Section 5.3) despite R\&D intensity } \\
\text { decline. }\end{array}$ \\
\hline
\end{tabular}

\section{2) Soft Innovation Resources Substituting for R\&D}

With the understanding that soft innovation resources can be considered as a crystal of the Internet, as demonstrated in Section 4.2, Table 13 demonstrates the soft innovation resources substituted for $G S C$, centered on R\&D, after $2010 .^{5}$

5 I (Internet) substitution for $J(R \& D)$

$$
\chi \equiv \frac{\text { Internet expenditure }}{\boldsymbol{R} \& \text { expenditure }}=\frac{\boldsymbol{I} \cdot \boldsymbol{p}_{i}}{J \cdot p_{j}} \quad \ln \chi=\ln \frac{I}{J}-\ln \frac{p_{j}}{p_{i}}=a+\left(\varepsilon_{j i}-1\right) \ln \frac{p_{j}}{p_{i}}
$$

where $\varepsilon_{j i}$ is elasticity of $i$ substitution for $j$ and when $\varepsilon_{j i}>1, p_{j}$ increase reacts to Internet expenditure increase ( $I$ substitutes for $J$ ). 
Table 13 The Correlation between the I/R Ratio and Relative Price in Finland (1995-2018).

$\begin{array}{cccc}\ln \frac{I}{R}=-2.01+0.63 D_{1} \ln \frac{P_{j}}{P_{i}}+2.17\left(D_{2}+D_{3}\right) \ln \frac{P_{j}}{P_{i}}+3.34 D_{1}-0.13 D^{*} \text { adj. } R^{2} 0.966 \quad D W 1.25 \\ (-2.30)(18.12) & (5.44) & (3.82) \quad(-2.39) & \end{array}$ $I$ : Internet (soft innovation resources); $R: \mathrm{R} \& \mathrm{D} ; P_{i}, P_{j}$ : prices of $I$ and $R$ (IPP price), respectively ${ }^{6}$. $D$ : dummy variables. $D_{1}-D_{3}$ : see Table $12 ; D^{*}: 1999,2000=1$, others $=0$.

The figures in parentheses indicate the t-statistics: all are significant at the $1 \%$ level.

\section{3) Soft Innovation Resources Spillover to Gross Tangible Capital}

Table 14 demonstrates that soft innovation resources (by using the Internet as a proxy) impacted the GTC share increase out of $G C$ after 2010, with particularly significance after 2016, which corresponds to the soft innovation resources substitution for GSC.

Table 14 The Impact of Soft Innovation Resources on the Gross Tangible Capital Increase in Finland (1995-2018)

$$
\begin{aligned}
& \ln K=-10.87-0.01 t-0.11 \mathrm{D}_{1} \ln R+0.59 \ln C \\
& (-2.78)(-3.63) \quad(-4.43) \quad(3.86) \\
& +1.15 D_{2} \ln I+2.77 D_{3} \ln I+12.68 D_{1}+7.34 D_{2}-0.01 D^{*} \quad \text { adj. } R^{2} 0.922 \quad D W 1.58 \\
& \text { (4.90) (3.31) (3.34) } \quad(1.94)^{* 1}(-2.65)
\end{aligned}
$$

where $K$ : share of $G T C$ out of gross fixed capital.

Backward elimination method with $10 \%$ criteria is used. $D$ : dummy variables. $D_{1}-D_{3}$ : see Table $12 ; D^{*}$ : $2003=1$, 0thers $=0$.

The figures in parentheses indicate the t-statistics: significant at the $1 \%$ level except ${ }^{* 1} 10 \%$.

All of these analyses demonstrated that soft innovation resources were substituted for $G S C$ spilled-over to $G T C$ and removed the structural impediments impeding its growth; thereby, $G T C$ contributed to $G C$ growth, leading to Finland's GDP growth resurgence.

\subsection{The Contribution of Soft Innovation Resources to the Resurgence}

Analyses in the preceding Sections suggested the following dynamism of soft innovation resources $(S I R s)$ in removing the structural impediments in GTC growth, which contributed to the resurgence of the Finnish GDP growth.

(i) The Advancement of the Internet aroused and induced SIRs (Fig. 1).

(ii) The Competitiveness Pact spurred the effective utilization of SIRs (see below).

(iii) SIRs substituted for GSC (centered on R\&D) were supported by uncaptured GDP (Table 13).

(iv) Through the substitution process, SIRs spilled-over and were incorporated into GTC via MFP (Table 14).

(v) MFP induced GTC by removing structural impediments to its growth (Table 14).

(vi) Increased GTC contributed to GDP growth (Table 11).

(vii) GDP growth, in turn, increased MFP, leading to a virtuous cycle.

\footnotetext{
6 Following Watanabe et al., (2015a), Internet price was estimated by using the following learning equation: 55.3 $I^{0.6}$ while R\&D price was based on IPP prices (National Accounts of Finland, 2018).
} 
(viii) In addition, GDP resurgence instilled confidence in the Competitiveness Pact.

The effective utilization of SIRs, as well as dynamism with its substitution for GSC and incorporation of spilled-over SIRs in GTC, depends largely on the co-evolutionary acclimatization capacity of the nation (Chew et al., 2010).

Activation of this dynamism can be attributed to Finland's institutional elasticity and spurring by the Competitiveness Pact.

In light of long lasting stagnation and the understanding of the significant role of trust, after years of negotiations and strikes, Finland's government convinced the country's unions in June 2016 to accept a reform pact, the Competitiveness Pact. The objective of this Pact was to improve the Finnish companies' price competitiveness, to increase exports and employment, and to accelerate economic growth. With this objective, the Pact intended to lead to the increase of annual working hours, to lower holiday bonuses, to freeze wages for a year, and to increase pension contributions for workers while lowering them for employers. The government promised to incentivize the deal with tax cuts. Prime Minister Juha Sipila pledged that Finland would be able to reduce unit labor costs to the same level as Sweden's in 2017, and to that of Germany's in three years. He also argued that greater business competitiveness would help generate new jobs (14 June 2016). This pledge was supported by the Governor of the Bank of Finland, Erkki Liikanen, in his statement on 31 March 2017 that the Competitiveness Pact was forecasted to improve cost competitiveness considerably. The Finnish economy posted $2.7 \%$ of GDP growth in 2017, higher than Eurozone, Sweden (2.4\%) and Germany (2.5\%). At the end of 2017, Oli Rehn, a board member of the Bank of Finland, reported proudly that the mood in the country had changed in a year from entrenched pessimism to half-euphoria which reflected in people's mood.

This historic and ambitious decision in June 2016 to shift away from centralized wage-setting towards company-level labor deals can largely be appreciated as a consequence of the effective utilization of SIRs, particularly of trust (Watanabe et al., 2016c). People's non-pessimistic mood in response to actual economic evidence has increased confidence in the Pact, as illustrated in Fig. 21, and aroused the nation's latent ability for sophisticated co-evolutionary acclimatization.

The full-fledged effects of the Competitiveness Pact should be expected; hence, further careful assessment should be indispensable. Some noteworthy signals to activate SIRs for removing structural impediments to GTC increase can be observed, and the effects of SIRs spillover have become a reality, as demonstrated in Fig. 21. 


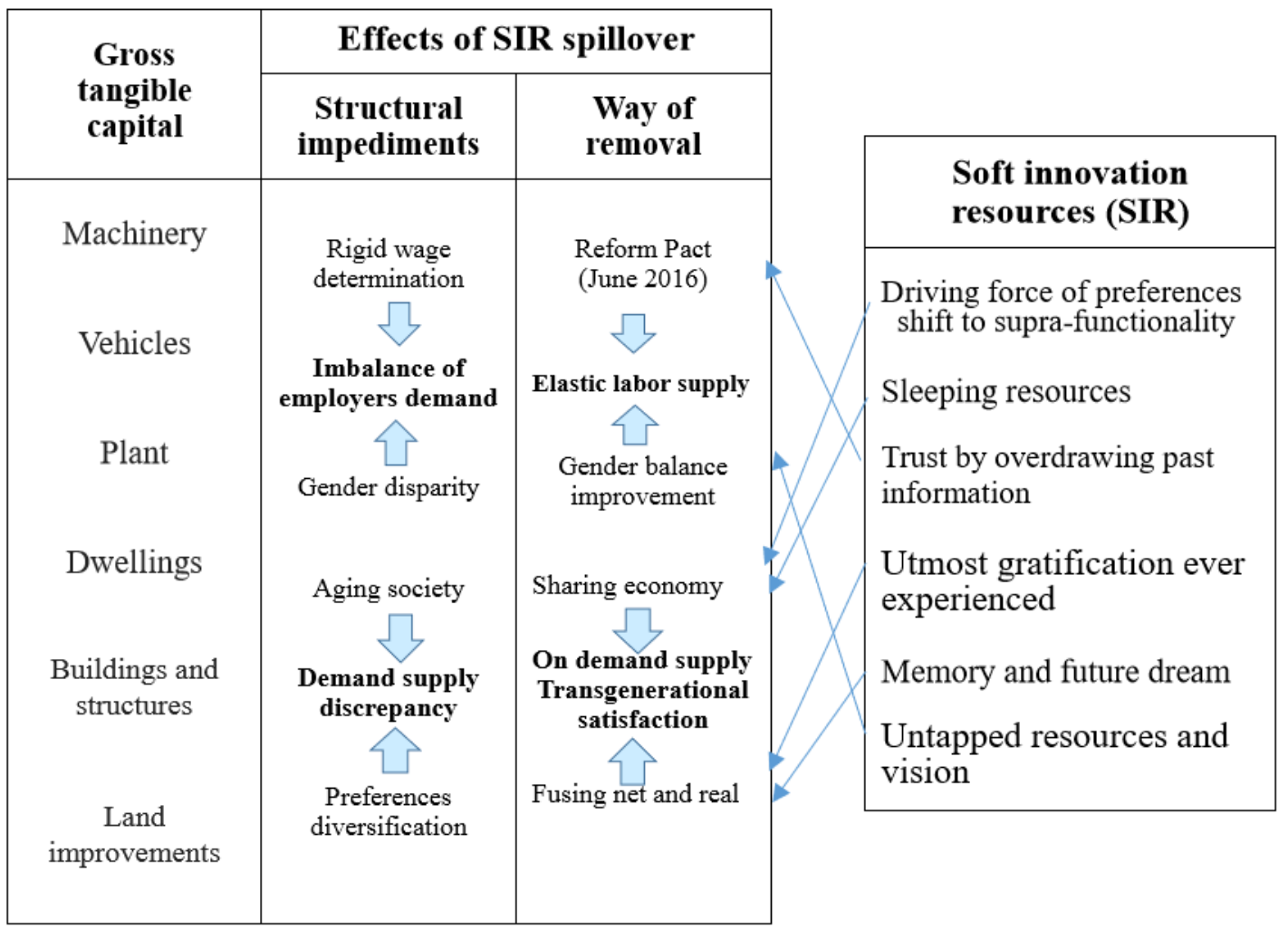

\section{Fig. 21. The Effects of Soft Innovation Resources Spillover in Finland.}

As a consequence of such efforts, the demand-supply discrepancy has dramatically decreased (OECD, 2017; Statistics Finland, 2018b) and enabled a GTC-positive contribution to GDP growth. For example, machinery and equipment have changed from long-lasting negative contributions into positive contributions to GDP growth from 2016, seen in: $-0.06 \%$ (2013); $-0.04 \%$ (2014); $-0.03 \%$ (2015) and $0.05 \%$ in 2016 (Watanabe et al., 2018a; Statistics Finland, 2018c). Efforts for gender balance improvement through utilizing ICT advancement have contributed to improving the imbalance of employers' demand as well (Watanabe et al., 2017b). Recent policy decisions, including the relaxation of car inspection laws (May 2018) and the taxi market liberalization (July 2018), have accelerated the effective utilization of SIRs, such as the driving force of the preferences shift to supra-functionality (Watanabe et al., $2018 c$ ) and sleeping resources (Watanabe 2016b). These decisions are expected to remove demand-supply discrepancies concerning the aging society and diversification of people's preferences and to enable on demand supply and trans generational satisfaction (Naveed et al., 2017).

All of these dynamisms demonstrate Finland's pioneer effort in transforming its development trajectory by means of the effective utilization of soft innovation resources based on neo open innovation in the digital economy. 


\section{Conclusion}

In light of a critical dilemma between R\&D expansion and productivity decline, which global ICT leaders have been confronting due to the two-faced nature of ICT, dynamism resulting in such a dilemma and countermeasures against it were analyzed.

On the basis of an empirical analysis, focusing on forefront endeavors to this dilemma of global ICT leaders, their transformative direction into a disruptive business model was investigated.

Noteworthy findings included:

(i) Transformation into a disruptive business model that creates supra-functionality beyond an economic value that satisfies people's preferences shift is a key direction.

(ii) For that, arousing and activating the self-propagating function indigenous to ICT and inducing a new functionality play a decisive role.

(iii) Soft innovation resources play a significant role in arousing and activating the latent self-propagating function.

(iv) Thus, neo open innovation that harnesses soft innovation resources can be a solution to this critical question.

(v) It depends largely on the assimilation capacity, which identifies, explores, and utilizes soft innovation resources and, then, absorbs and assimilates them into the whole value chain of production, diffusion, and consumption.

(vi) Triggered by the Competitiveness Pact in June 2016, Finland, based on neo-open innovation, has transformed into the effective utilization of soft innovation resources.

(vii) This success can be attributed to the substitution of soft innovation resources for gross service capital, center on R\&D, which spilled-over to gross tangible capital and removed the structural impediments to its growth.

These findings give rise to the following insightful suggestions for sustainable growth in the digital economy that incorporates a two-faced nature:

(i) Neo open innovation should be sought on a priority basis.

(ii) The development of assimilation capacity should be endeavored.

(iii) Further exploration and utilization of soft innovation resources should be encouraged.

(iv) New concepts of R\&D investment in the aforementioned transformation should be conceptualized.

(v) Similar dynamism, such as gross capital to export-driven growth, should be sought.

This analysis provides new insights for exploring a practical solution to the dilemma between R\&D expansion and productivity decline in the digital economy.

Future works should focus on further elucidation of the sources of success of neo open innovation. The transformative direction of gross service capital, in view of the effective 
utilization of soft innovation resources, should be explored. In this context, Amazon's conspicuous jump up to a world R\&D leader should be further analyzed.

\section{Acknowledgement}

The research leading to these results is the part of a project: Platform Value Now: Value capturing in the fast emerging platform ecosystems, supported by the Strategic Research Council at the Academy of Finland [grant number 293446]. 


\section{Appendix 1 Basic Statistics for the Analyses}

Table A1 Trend in GDP Growth Rate in ICT Advanced 12 Countries (2012-2018)

\begin{tabular}{lcccccccc}
\hline & 2012 & 2013 & 2014 & 2015 & 2016 & 2017 & 2018 & $\begin{array}{c}\text { ICT } \\
\text { Ranking } \\
(2014)\end{array}$ \\
\hline Finland & -1.43 & -0.76 & -0.63 & 0.14 & 2.48 & 2.80 & 2.65 & 1 \\
\hline Singapore & 4.08 & 5.11 & 3.88 & 2.24 & 2.4 & 3.62 & 2.93 & 2 \\
\hline Sweden & -0.30 & 1.24 & 2.6 & 4.46 & 2.68 & 2.11 & 2.42 & 3 \\
\hline Netherlands & -1.03 & -0.13 & 1.42 & 1.96 & 2.19 & 2.87 & 2.81 & 4 \\
\hline Norway & 2.72 & 1.04 & 1.98 & 1.97 & 1.09 & 1.92 & 2.11 & 5 \\
\hline Switzerland & 1.01 & 1.88 & 2.49 & 1.27 & 1.59 & 1.67 & 3.01 & 6 \\
\hline USA & 2.25 & 1.84 & 2.45 & 2.88 & 1.57 & 2.22 & 2.88 & 7 \\
\hline UK & 1.45 & 2.05 & 2.95 & 2.35 & 1.79 & 1.66 & 1.36 & 9 \\
\hline Germany & 0.69 & 0.61 & 2.18 & 1.48 & 2.16 & 2.46 & 1.91 & 12 \\
\hline Denmark & 0.23 & 0.94 & 1.62 & 1.61 & 1.97 & 2.28 & 1.96 & 13 \\
\hline Israel & 2.20 & 4.20 & 3.48 & 2.63 & 3.96 & 3.29 & 3.60 & 15 \\
\hline Japan & 1.50 & 2.00 & 0.38 & 1.35 & 0.96 & 1.74 & 1.14 & 16 \\
\hline
\end{tabular}

Sources: World Economic Outlook Database (IMF, October 2018b); The Global Information Technology Report 2014 (World Economic Forum, 2014). 
Table A2 Contribution of Growth Rate of Gross Fixed Capital (GC) Formation in Finland and Singapore (2012-2017) - \%.

\begin{tabular}{|c|c|c|c|c|c|c|c|}
\hline & & 2012 & 2013 & 2014 & 2015 & 2016 & 2017 \\
\hline \multirow{8}{*}{ 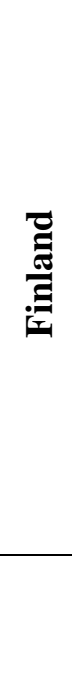 } & $\boldsymbol{\kappa}$ & 21.40 & 21.68 & 22.14 & 20.85 & 19.04 & 17.89 \\
\hline & $\lambda$ & 78.60 & 78.32 & 77.86 & 79.15 & 80.96 & 82.11 \\
\hline & $\Delta \mathrm{GC} / \mathrm{GC}$ & -0.34 & -9.98 & -0.08 & 0.22 & 1.49 & 1.19 \\
\hline & $\Delta \boldsymbol{k}$ & -0.76 & 0.27 & 0.46 & -1.29 & -1.81 & -1.16 \\
\hline & $\Delta \lambda$ & 0.76 & -0.27 & -0.46 & 1.29 & 1.81 & 1.16 \\
\hline & $\Delta \kappa+\kappa \Delta G C / G C$ & -0.83 & -1.89 & 0.44 & -1.24 & -1.53 & -0.94 \\
\hline & $\Delta \lambda+\lambda \Delta \mathrm{GC} / \mathrm{GC}$ & 0.49 & -8.09 & -0.52 & 1.46 & 3.02 & 2.13 \\
\hline & & 2012 & 2013 & 2014 & 2015 & 2016 & 2017 \\
\hline \multirow{7}{*}{ 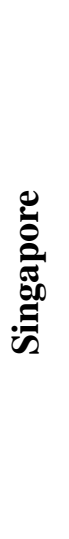 } & $\boldsymbol{\kappa}$ & 14.60 & 18.95 & 23.23 & 22.73 & 21.45 & 22.87 \\
\hline & $\lambda$ & 85.40 & 81.05 & 76.77 & 77.27 & 78.55 & 77.13 \\
\hline & $\Delta \mathrm{GC} / \mathrm{GC}$ & 2.20 & 1.69 & 1.87 & 0.54 & -0.10 & -0.58 \\
\hline & $\Delta \kappa$ & 0.11 & 4.35 & 4.28 & -0.50 & -1.28 & 1.42 \\
\hline & $\Delta \lambda$ & -0.11 & -4.35 & -4.28 & 0.50 & 1.28 & -1.42 \\
\hline & $\Delta \kappa+\kappa \Delta G C / G C$ & 0.43 & 4.67 & 4.71 & -0.38 & -1.30 & 1.29 \\
\hline & $\Delta \lambda+\lambda \Delta \mathrm{GC} / \mathrm{GC}$ & 1.77 & -2.98 & -2.84 & 0.92 & 1.20 & -1.87 \\
\hline
\end{tabular}

Sources: National Accounts of Finland (Statistics Finland, 2018); National Accounts of Singapore (Department of Statistics Singapore, 2018).

Note

$G C$ can be decomposed as follow:

$G C=\kappa G C+\lambda G C$

where $\kappa$ and $\lambda$ : share of $G S C$ and $G T C$, respectively. $\kappa+\lambda=1$

Differentiate by time $t$ :

$\frac{d G C}{d t}=\Delta G C=(\Delta \kappa \cdot G C+\kappa \cdot \Delta G C)+(\Delta \lambda \cdot G C+\lambda \cdot \Delta G C)$

Thus, growth rate can be depicted as follows:

$$
\begin{aligned}
& \frac{\Delta G C}{G C}=\left(\Delta \kappa+k \cdot \frac{\Delta G C}{G C}\right)+\left(\Delta \lambda+\lambda \cdot \frac{\Delta G C}{G C}\right) \\
& \text { GSC contribution GTC contribution }
\end{aligned}
$$


Table A3 Trend in R\&D intensity in Finland and Singapore (1995-2016)

\begin{tabular}{|c|c|c|c|c|}
\hline & \multicolumn{2}{|c|}{ R\&D intensity (\%) } & \multicolumn{2}{|c|}{ R\&D intensity $(1995=100)$} \\
\hline & Finland & Singapore & Finland & Singapore \\
\hline 1995 & 2.20 & 1.10 & 100.0 & 100.0 \\
\hline 1996 & 2.44 & 1.32 & 110.6 & 120.2 \\
\hline 1997 & 2.62 & 1.42 & 119.0 & 129.0 \\
\hline 1998 & 2.79 & 1.74 & 126.4 & 158.4 \\
\hline 1999 & 3.06 & 1.82 & 138.7 & 165.6 \\
\hline 2000 & 3.25 & 1.82 & 147.3 & 166.0 \\
\hline 2001 & 3.20 & 2.02 & 145.1 & 184.2 \\
\hline 2002 & 3.26 & 2.07 & 147.8 & 188.5 \\
\hline 2003 & 3.30 & 2.03 & 149.8 & 184.7 \\
\hline 2004 & 3.31 & 2.10 & 150.4 & 191.8 \\
\hline 2005 & 3.33 & 2.16 & 151.1 & 197.0 \\
\hline 2006 & 3.34 & 2.13 & 151.4 & 194.5 \\
\hline 2007 & 3.35 & 2.34 & 151.8 & 213.0 \\
\hline 2008 & 3.55 & 2.62 & 160.9 & 238.9 \\
\hline 2009 & 3.75 & 2.16 & 170.1 & 196.8 \\
\hline 2010 & 3.73 & 2.01 & 169.1 & 183.5 \\
\hline 2011 & 3.64 & 2.15 & 165.1 & 195.6 \\
\hline 2012 & 3.42 & 1.99 & 155.1 & 181.8 \\
\hline 2013 & 3.29 & 1.99 & 149.1 & 181.0 \\
\hline 2014 & 3.17 & 2.16 & 143.8 & 196.9 \\
\hline 2015 & 2.90 & 2.28 & 131.4 & 208.3 \\
\hline 2016 & 2.74 & 2.22 & 124.4 & 202.8 \\
\hline
\end{tabular}

Sources: Same as Table A2. 
Table A4 Trends in Techno-economic Structure in Finland (1994-2018)

\begin{tabular}{|c|c|c|c|c|c|c|c|c|}
\hline Period & Time & Real GDP & $\begin{array}{l}\text { Real GDP } \\
\text { growth rate }\end{array}$ & $R \& D$ intensity & $\begin{array}{l}\text { Real R\&D } \\
\text { expenditure }\end{array}$ & $\begin{array}{c}\text { Internet } \\
\text { dependence }\end{array}$ & $\begin{array}{c}\text { Final } \\
\text { consumption } \\
\text { expenditure }\end{array}$ & GTC/GC \\
\hline Year & $t$ & $\begin{array}{c}V \text { (bil. E at } 2010 \\
\text { prices) }\end{array}$ & $\begin{array}{c}G G R \\
\%\end{array}$ & $\begin{array}{l}R V \\
\%\end{array}$ & $\begin{array}{c}R \text { (bil. E at } \\
2010 \text { prices) }\end{array}$ & $\begin{array}{l}I \\
\%\end{array}$ & $\begin{array}{c}C \text { (bil. E at } 2010 \\
\text { prices) }\end{array}$ & $\kappa$ \\
\hline 1994 & 1 & 118.4 & 3.9 & 2.21 & 2.6 & 4.9 & 94.7 & 80.2 \\
\hline 1995 & 2 & 123.4 & 4.2 & 2.20 & 2.7 & 13.9 & 98.9 & 80.6 \\
\hline 1996 & 3 & 127.9 & 3.7 & 2.45 & 3.1 & 16.8 & 102.1 & 80.9 \\
\hline 1997 & 4 & 135.9 & 6.3 & 2.62 & 3.6 & 19.5 & 105.6 & 80.5 \\
\hline 1998 & 5 & 143.3 & 5.4 & 2.79 & 4.0 & 25.5 & 109.7 & 80.6 \\
\hline 1999 & 6 & 149.7 & 4.4 & 3.06 & 4.6 & 32.3 & 112.9 & 78.3 \\
\hline 2000 & 7 & 158.1 & 5.6 & 3.25 & 5.1 & 37.3 & 114.9 & 77.9 \\
\hline 2001 & 8 & 162.2 & 2.6 & 3.20 & 5.2 & 43.1 & 118.0 & 77.3 \\
\hline 2002 & 9 & 164.9 & 1.7 & 3.26 & 5.4 & 62.4 & 121.0 & 77.0 \\
\hline 2003 & 10 & 168.2 & 2.0 & 3.30 & 5.6 & 69.2 & 125.1 & 76.2 \\
\hline 2004 & 11 & 174.8 & 3.9 & 3.31 & 5.8 & 72.4 & 128.8 & 77.1 \\
\hline 2005 & 12 & 179.7 & 2.8 & 3.33 & 6.0 & 74.5 & 132.5 & 77.1 \\
\hline 2006 & 13 & 186.9 & 4.1 & 3.34 & 6.2 & 79.7 & 136.7 & 77.1 \\
\hline 2007 & 14 & 196.6 & 5.2 & 3.35 & $6.6=$ & 80.8 & 140.6 & 78.0 \\
\hline 2008 & 15 & 198.0 & 0.7 & 3.55 & 7.0 & 82.5 & 143.4 & 77.6 \\
\hline 2009 & 16 & 181.7 & -8.3 & 3.75 & 6.8 & 83.7 & 141.3 & 75.9 \\
\hline 2010 & 17 & 187.1 & 3.0 & 3.73 & 7.0 & 86.9 & 144.3 & 75.9 \\
\hline 2011 & 18 & 191.9 & 2.6 & 3.64 & 7.0 & 88.8 & 147.1 & 77.8 \\
\hline 2012 & 19 & 189.2 & -1.4 & 3.42 & 6.5 & 90.0 & 147.7 & 78.6 \\
\hline 2013 & 20 & 187.7 & -0.8 & 3.29 & 6.2 & 91.6 & 147.7 & 78.3 \\
\hline 2014 & 21 & 186.6 & -0.6 & 3.17 & 5.9 & 92.0 & 148.3 & 77.9 \\
\hline 2015 & 22 & 186.8 & 0.1 & 2.90 & 5.4 & 92.8 & 150.1 & 79.1 \\
\hline 2016 & 23 & 191.4 & 2.5 & 2.74 & 5.2 & 93.5 & 152.8 & 81.0 \\
\hline 2017 & 24 & 196.8 & 2.8 & 2.75 & 5.4 & $94.1^{*}$ & 155.1 & 82.1 \\
\hline 2018 & 25 & 202.0 & 2.7 & $2.75^{*}$ & 5.5 & $94.7^{*}$ & $158.6^{*}$ & $83.5^{*}$ \\
\hline
\end{tabular}

Sources: Real GDP and Real GDP growth rate: World Economic Outlook Database (IMF, October. 2018b); R\&D intensity: Ratio of R\&D expenditure and GDP at current prices by National Accounts of Finland (Statistics of Finland, 2018) (* is estimated based on trends in 2014-2016); Real R\&D expenditure: Real GDP * R\&D intensity; Internet dependence: World Telecommunication/ICT Indicators Database (ITU, 2018) (*are estimated based on trends in 2014-2016); Final consumption: National Accounts of Finland (Statistics of Finland, 2018) (*is estimated based on trends in 2014-2016); GTC/GC: National Accounts of Finland (Statistics of Finland, 2018) (* is estimated based on trends in 2014-2016). 


\section{Appendix 2 Trends in the People's Preferences}

Table A5 Trends in the People's Preferences Sift in Japan (1972-2018)

\begin{tabular}{|c|c|c|c|c|}
\hline Year & Economic-functionality $^{1}$ & $\begin{array}{l}\text { Supra-functionality }^{2} \\
\text { beyond economic value }\end{array}$ & Others $^{3}$ & Total \\
\hline 1972 & 37.3 & 40.0 & 22.7 & 100 \\
\hline 1973 & 35.3 & 40.3 & 24.4 & 100 \\
\hline 1974 & 36.4 & 41.5 & 22.2 & 100 \\
\hline 1975 & 37.8 & 41.1 & 21.1 & 100 \\
\hline 1976 & 39.9 & 41.4 & 18.8 & 100 \\
\hline 1977 & 40.1 & 41.1 & 18.8 & 100 \\
\hline 1978 & 39.5 & 40.4 & 20.1 & 100 \\
\hline 1979 & 40.3 & 40.9 & 18.8 & 100 \\
\hline 1980 & 39.8 & 42.2 & 18.0 & 100 \\
\hline 1981 & 38.8 & 44.3 & 16.9 & 100 \\
\hline 1982 & 37.6 & 44.8 & 17.6 & 100 \\
\hline 1983 & 36.8 & 46.4 & 16.8 & 100 \\
\hline 1984 & 36.8 & 46.5 & 16.7 & 100 \\
\hline 1985 & 32.9 & 49.6 & 17.5 & 100 \\
\hline 1986 & 32.7 & 49.1 & 18.2 & 100 \\
\hline 1987 & 34.0 & 49.6 & 16.4 & 100 \\
\hline 1988 & 32.0 & 50.3 & 17.7 & 100 \\
\hline 1989 & 32.7 & 49.3 & 18.0 & 100 \\
\hline 1990 & 30.8 & 53.0 & 16.2 & 100 \\
\hline 1991 & 30.5 & 52.0 & 17.5 & 100 \\
\hline 1992 & 27.3 & 57.2 & 15.5 & 100 \\
\hline 1993 & 29.0 & 57.4 & 13.6 & 100 \\
\hline 1994 & 30.0 & 57.2 & 12.8 & 100 \\
\hline 1995 & 28.1 & 56.8 & 15.1 & 100 \\
\hline 1996 & 27.9 & 58.8 & 13.3 & 100 \\
\hline 1997 & 30.1 & 56.3 & 13.6 & 100 \\
\hline 1999 & 29.3 & 57.0 & 13.7 & 100 \\
\hline 2002 & 27.4 & 60.7 & 11.9 & 100 \\
\hline 2003 & 28.7 & 60.0 & 11.3 & 100 \\
\hline 2004 & 29.1 & 59.0 & 11.9 & 100 \\
\hline 2005 & 28.4 & 57.8 & 13.8 & 100 \\
\hline 2006 & 30.4 & 62.9 & 6.7 & 100 \\
\hline 2007 & 28.6 & 62.6 & 8.8 & 100 \\
\hline 2008 & 30.2 & 62.6 & 7.2 & 100 \\
\hline 2009 & 30.2 & 60.5 & 9.3 & 100 \\
\hline 2010 & 31.1 & 60.0 & 8.9 & 100 \\
\hline 2011 & 31.0 & 61.4 & 7.6 & 100 \\
\hline 2012 & 30.1 & 64.0 & 5.9 & 100 \\
\hline 2013 & 30.3 & 61.8 & 7.9 & 100 \\
\hline 2014 & 31.0 & 63.1 & 5.9 & 100 \\
\hline 2015 & 31.9 & 62.0 & 6.1 & 100 \\
\hline 2016 & 31.3 & 60.2 & 8.5 & 100 \\
\hline 2017 & 29.2 & 62.6 & 8.2 & 100 \\
\hline
\end{tabular}

\footnotetext{
${ }^{1}$ Wealth of things: Material affluence (emphasis should still be put on material affluence for future life).

${ }^{2}$ Richness of Heart: Spiritual happiness (because a reasonable level of material affluence has been achieved,

future emphasis should be put on spiritual happiness and comfortable life).

${ }^{3}$ Cannot identify explicitly.
}

Source: National Survey of Lifestyle Preferences (Japan Cabinet Office, 2018). 


\section{References}

[1] Ahmad, N. and Schreyer, P., 2016. Are GDP and Productivity Measures up to the Challenges of the Digital Economy? International Productivity Monitor 30, Spring, 4-27.

[2] Bloomberg, 2017. 2017 Global Innovation 1000 Study. Bloomberg, New York.

[3] Bloomberg, 2018. Company Overview of Annual Reports. Bloomberg, New York.

[4] Brynjolfsson, E. and McAfee, A., 2014. The Second Machine Age: Work, Progress, and Prosperity in a Time of Brilliant Technologies. W.W. Norton \& Company, New York.

[5] Byrne, D. and Corrado, C., 2016. ICT Prices and ICT Services: What do They Tell about Productivity and Technology? Economic Program Working Paper Series, EPWP \#16-05, The Conference Board, New York.

[6] Chew, M., Watanabe, C. \& Tou, Y., 2010. Technology Leapfrogging: Findings from Singapore's Water Industry. Journal of Technology Management for Growing Economies 1 (2) 29-47.

[7] Cowen, T., 2011. The Great Stagnation: How America Ate All the Low-Hanging Fruit of Modern History, Got Sick, and Will (Eventually) Feel Better. A Penguin Special from Dutton, Penguin, New York.

[8] Department of Broadband, Communications and the Digital Economy (DBCDE), 2009. Digital Economy Future Directions. DBCDE, Camberra.

[9] Department of Statistics Singapore, 2018. National Accounts of Singapore. Department of Statistics Singapore, Singapore.

[10] Dervis, K. and Qureshi, Z., 2016. The Productivity Slump - Fact or Fiction: The Measurement Debate. Global Economy and Development at Brookings, Washington, D.C.

[11] EU, 2017a. Economics of Industrial Research and Innovation, EU, Brussels.

[12] EU, 2017b. The Internet of Things: Digital Single Market. EU, Brussels.

[13] Feldstein, M., 2017. Understanding the Real Growth of GDP, Personal Income, and Productivity. Journal of Economic Perspectives 31 (2), 145-164.

[14] Hutchenreiter, G., Zuniga, P. \& Weber J., (2017). "OECD Review of Innovation Policy: Finland Assessment and Recommendations," Launch Seminar, Helsinki.

[15] International Monetary Fund (IMF), 2017a. World Economic Outlook Database 2017. IMF, Washington, D.C.

[16] International Monetary Fund (IMF), 2017b. Measuring the Digital Economy: IMF Statistical Forum. IMF, Washington D.C.

[17] International Monetary Fund (IMF), 2018a. Measuring the Digital Economy. Washington, D.C.

[18] International Monetary Fund (IMF), 2018b. World Economic Outlook Database 2018, IMF, Washington, D.C.

[19] International Telecommunication Union (ITU), 2018. World Telecommunication/ICT Indicators Database, ITU, Geneva.

[20] Japan Cabinet Office (JCO), 2018. National Survey of Lifestyle Preferences. JCO, Tokyo.

[21] Kahre, C., Hoffmann, D. and Ahlemann, F., 2017. Beyond business-IT Alignment-Digital Business Strategies as a Paradigmatic Shift: A Review and Research Agenda, Proceedings of the 50th Hawaii International Conference on System Sciences, 4706-4715.

[22] Lowrey, A., 2011. Freaks, Geeks, and GDP. Slate. http://www.slate.com/articles/business/moneybox/2011/03/freaks_geeks_and_gdp.html (accessed 20.06.2017). 
[23] McDonagh, D., 2008. Satisfying Needs beyond the Functional: The Changing Needs of the Silver Market Consumer. Presented at the International Symposium on the Silver Market Phenomenon - Business Opportunities and Responsibilities in the Aging Society, Tokyo, Japan.

[24] McKinsey Global Institute, 2015. The Internet of Things: Mapping the Value beyond the Hype. McKinsey \& Company, San Francisco.

[25] Ministry of Internal Affairs and Communication (MIC), 2011. White Paper on Japan's Information and Communication. MIC, Tokyo.

[26] Naveed, K., Watanabe, C. and Neittaanmäki, P., 2017. Co-evolution between Streaming and Live Music Leads a Way to the Sustainable Growth of Music Industry: Lessons from the US Experiences, Technology in Society 50, 1-19.

[27] Naveed, K., Watanabe, C. and Neittaanmäki, P., 2018. The Transformative Direction of Innovation toward an IoT-based Society: Increasing Dependency on Uncaptured GDP in Global ICT Firms. Technology in Society 53, 23-46.

[28] OECD, 2016. OECD Observer: The Digital Economy. OECD, Paris.

[29] OECD, 2017. OECD Review of Innovation Policy: Finland Assessment and Recommendation. OECD, Paris.

[30] Pew Research Center, 2016. Smartphone Ownership and Internet Usage Continues to Climb in Emerging Economies. Pew Research Center, Washington, D.C.

[31] Schelling, T.C., 1998. Social mechanisms and social dynamics, in Hedstrom, P. and Swedberg, R. eds., Social Mechanisms: An Analytical Approach to Social Theory. Cambridge Univ. Press, Cambridge, 32-43.

[32] Statistics Finland, 2018. National Accounts of Finland. Statistics Finland, Helsinki.

[33] Statistics Finland, 2018b. The Labor Market in Finland. Statistics Finland, Helsinki.

[34] Statistics Finland, 2018c. Statistics Finland's PX-Web databases. Statistics Finland, Helsinki

[35] Tapscott, D., 1994. The Digital Economy: Promise and Peril in the Age of Networked Intelligence. McGraw-Hill, New York.

[36] The Economist, 2018. Schumpeter: The Tech Sell-off. The Economist, November $3^{\text {rd }} 2018$.

[37] The World Bank, 2016. Digital Dividends. The World Bank, Washington D.C.

[38] Tou, Y., Moriya, K., Watanabe, C., Ilmola, L. and Neittaanmäki, P., 2018a. Soft Innovation Resources: Enabler for Reversal in GDP Growth in the Digital Economy. International Journal of Managing Information Technology 10 (3), 21-39.

[39] Tou, Y., Watanabe, C., Ilmola, L., Moriya, K. and Neittaanmäki, P., 2018b. Hybrid Role of Soft Innovation Resources: Finland's Notable Resurgence in the Digital Economy. International Journal of Managing Information Technology 10 (4), 1-22.

[40] Tou, Y., Watanabe, Moriya, K. and Neittaanmäki, P., 2019. Neo Open Innovation in the Digital Economy: Harnessing Soft Innovation Resources. International Journal of Managing Information Technology 10 (4), 53-75.

[41] UNESCO, 2015. Countries of All Income Levels Nurturing a Digital Economy. UNESCO Science Report: towards 2030. UNESCO, Paris.

[42] US Council on Competitiveness., 2016. No Recovery: An Analysis on Long-term U.S. Productivity Decline. Washington, D.C.

[43] Watanabe, C., Kondo, R., Ouchi, N., Wei, H. and Griffy-Brown, C., 2004. Institutional Elasticity as a Significant Driver of IT Functionality Development. Technological Forecasting and Social Change 71 (7), 723-750. 
[44] Watanabe, C., Lei, S. and Ouchi, N., 2009. Fusing Indigenous Technology Development and Market Learning for Greater Functionality Development: An Empirical Analysis of the Growth Trajectory of Canon Printers. Technovation 29 (2), 265-283.

[45] Watanabe, C., Naveed, K. and Zhao, W., 2015a. New Paradigm of ICT Productivity: Increasing Role of Un-captured GDP and Growing Anger of Consumers. Technology in Society 41, 21-44.

[46] Watanabe, C., Naveed, K. and Neittaanmäki, P., 2015b. Dependency on Un-captured GDP as a Source of Resilience beyond Economic Value in Countries with Advanced ICT Infrastructure: Similarities and Disparities between Finland and Singapore. Technology in Society 42, 104-122.

[47] Watanabe, C., Naveed, K., Neittaanmäki, P. and Tou, Y., 2016a. Operationalization of Un-captured GDP: The Innovation Stream under New Global Mega-trends. Technology in Society $45,58-77$.

[48] Watanabe, C., Naveed, K., Neittaanmäki, P. and Tou, Y., 2016b. Co-evolution of Three Mega Trends Nature Uncaptured GDP: Uber's Ride-sharing Revolution, Technology in Society 46, 164-185.

[49] Watanabe, C., Naveed, K. and Neittaanmäki, P., 2016c. Co-evolution between Trust in Teachers and Higher Education toward Digitally-rich Learning Environments, Technology in Society 48, 70-96.

[50] Watanabe, C., Naveed, K. and Neittaanmäki, P., 2017a. Consolidated Challenge to Social Demand for Resilient Platforms: Lessons from Uber's Global Expansion. Technology in Society 48, 33-53.

[51] Watanabe, C., Naveed, K. and Neittaanmäki, P., 2017b. ICT-driven Disruptive Innovation Nurtures Uncaptured GDP: Harnessing Woemen's Potential as Untapped Resources., Technology in Society 51, 81-101.

[52] Watanabe, C., Moriya, K., Tou, Y. and Neittaanmäki, P., 2018a. Structural Sources of a Productivity Decline in the Digital Economy, International Journal of Managing Information Technology 10 (1), 1-20.

[53] Watanabe, C., Moriya, K., Tou, Y. and Neittaanmäki, P., 2018b. Consequences of the Digital Economy: Transformation of the Growth Concept. International Journal of Managing Information Technology 10 (2), 21-39.

[54] Watanabe, C., Naveed, N. and Neittaanmäki, P., 2018c. Digital Solutions Transform the Forest-based Bioeconomy into a Digital Platform Industry: A Suggestion for a Disruptive Business Model in the Digital Economy. Technology in Society 54, 168-188.

[55] Watanabe, C., Tou, Y. and Neittaanmäki, P., 2018c. A New Paradox of the Digital Economy: Structural Sources of the Limitation of GDP Statistics. Technology in Society 55, 9-23.

[56] Watanabe, C., Naveed, K., Tou, Y. and Neittaanmäki, P., 2018d. Measuring GDP in the Digital Economy: Increasing Dependence on Uncaptured GDP. Technological Forecasting and Social Change 137, 226-240.

[57] Watanabe, C., Naveed, N. and Neittaanmäki, P., 2018e. Digitalized Bioeconomy: Planned Obsolescence-driven Economy Enabled by Co-evolutionary Coupling. Technology in Society 55 , in print.

[58] World Economic Forum (WEF), 2014. The Global Information Technology Report 2014. WEF, Geneva.

[59] World Economic Forum (WEF), 2016. The Global Information Technology Report 2016. WEF, Geneva.

[60] World Economic Forum (WEF), 2017. The Global Information Technology Report 2017. WEF, Geneva.

[61] Ylhainen, I., 2017. Challenges of Measuring the Digital Economy. 
https://www.sitra.fi/en/articles/challenges-measuring-digital-economy/

\section{Authors' Curriculum Vitae}

Yuji Tou graduated from the Tokyo Institute of Technology, Japan, and is currently an associate professor at the Tokyo Institute of Technology, Japan (tou.yuji@gmail.com).

Chihiro Watanabe graduated from the University of Tokyo, Japan, and is currently Professor Emeritus at the Tokyo Institute of Technology, a research professor at the University of Jyväskylä, Finland, and a research scholar at the International Institute for Applied Systems Analysis (IIASA). (watanabe.c.pqr@gmail.com).

Kuniko Moriya graduated from Aoyama Gakuin University, Japan, and is currently Director of the Bank of Japan, and a research scholar at the University of Jyväskylä, Finland (kuniko.moriya@boj.or.jp).

Pekka Neittaanmäki graduated from the University of Jyväskylä with a degree in Mathematics. He is currently Professor of the Faculty of Information Technology, University of Jyväskylä, Finland. (pekka.neittaanmaki@jyu.fi). 


\section{Highlights}

\section{Harnessing Soft Innovation Resources Leads to Neo Open Innovation}

1. Neo open innovation in the digital economy was conceptualized

2. Soft innovation resources lead to neo open innovation was demonstrated

3. A solution to a dilemma between input increases and output decreases was provided

4. Suggestions for drafting a roadmap towards neo open innovation were provided

5. Survival strategies of global ICT leaders were analyzed 
Digital value $V$ created by in an IoT society can be depicted as follows:

$V=F\left(X, I_{g}\right)$

where $I_{g}$ : gross ICT stock $=I$ (ICT stock) $+J$ (internet dependence); $X$ : other production factors.

Translog (transcendental logarithmic) expansion on the first term: $\ln V=p+q \ln X+r \ln I_{\mathrm{g}}$ where $p, q$, and $r$ : coefficients.

$I_{\mathrm{g}}$ embodies into $X$ in an IoT society as follows:

$$
X=F\left(I_{\mathrm{g}}\right) \quad \ln X=p_{\mathrm{x}}+r_{\mathrm{x}} \ln I_{\mathrm{g}}
$$

where $p_{\mathrm{x}}$ and $r_{\mathrm{x}}$ : coefficients.

Synchronizing equations (2) and (3):

$$
\begin{aligned}
& \begin{array}{l}
\ln V=p+q\left(p_{\mathrm{x}}+r_{\mathrm{x}} \ln I_{\mathrm{g}}\right)+r \ln I_{\mathrm{g}}=\left(p+q \cdot p_{\mathrm{x}}\right)+\left(q \cdot r_{\mathrm{x}}+r\right) \ln I_{\mathrm{q}} \\
\quad \equiv \alpha+\beta \ln I_{\mathrm{g}}
\end{array} \\
& \text { where } \alpha=p+q \cdot P_{\mathrm{x}}, \quad \beta=q \cdot r_{\mathrm{x}}+r .
\end{aligned}
$$

This demonstrates that $V$ is governed by $I_{\mathrm{g}}$ under the above circumstances.

As the Internet permeates into ICT in general, $I_{\mathrm{g}}$ increases proportional to gross $R \& D$ represented by gross $R \& D$ expenditure (see Note 1).

$$
\begin{aligned}
I_{\mathrm{g}} & =I+J \approx \frac{R_{\mathrm{i}}}{\rho_{i}+g_{\mathrm{i}}}+\frac{R_{\mathrm{j}}}{\rho_{\mathrm{j}}+g_{\mathrm{j}}} \approx \frac{R_{\mathrm{i}}}{\rho+g}+\frac{R_{\mathrm{j}}}{\rho+g}=\frac{R_{\mathrm{i}}+R_{\mathrm{j}}}{\rho+g} \\
& =\frac{R}{\rho+g}
\end{aligned}
$$

where $R_{\mathrm{i}}: \mathrm{R} \& \mathrm{D}$ related to the Internet, and $R_{\mathrm{i}}: \mathrm{R} \& \mathrm{D}$ related to other ICT; $\rho$ : rate of obsolescence of ICT, and $g:$ R\&D growth rate at initial stage.

\section{Note 1 ICT stock at time $t$}

ICT stock can be appropriated proportional to gross R\&D:

$I_{t}=R_{t-m}+(1-\rho) T_{t-1}$ and $I_{0}=\frac{R_{1-m}}{\rho+g}$

Therefore, $I_{t}=\frac{R_{t+1-m}}{\rho+g}$, when $t \gg m-1, I_{t} \approx \frac{R_{t}}{\rho+g}$

where $m$ : time-lag between R\&D and commercialization.

Substituting equation (5) for $I g$ in equation (4):

$$
\begin{aligned}
& \ln V=\alpha+\beta \ln \frac{R}{\rho+g}=\alpha-\beta \ln (\rho+g)+\beta \ln R \\
& \equiv \alpha^{\prime}+\beta \ln R \\
& \text { where } \alpha^{\prime}=\alpha-\beta \ln (\rho+g) \text {. }
\end{aligned}
$$

Thus, digital value is governed by gross $R \& D$ in an IoT society.

Given the logistic growth nature of ICT, $V$ can be developed by an $R$-driven logistic growth function.

$$
V \approx F(R), \frac{d V}{d R}=\frac{\partial V}{\partial R} \cdot \frac{d R}{d R}=\frac{\partial V}{\partial R}=a V\left(1-\frac{V}{N}\right)
$$


where $N$ : carrying capacity; and $a$ : velocity of diffusion.

Equation (7) develops the following simple logistic growth function $(S L G)$ :

$$
V_{\mathrm{s}}(R)=\frac{N}{1+b e^{-a R}}
$$

where $b$ : coefficient indicating the initial level of diffusion.

This function leads to bipolarization as follows:

$$
\begin{aligned}
& b e^{-a R} \equiv \frac{1}{x} \\
& \begin{aligned}
\frac{\partial V}{\partial R} & =a V\left(1-\frac{V}{N}\right)=a N \cdot \frac{1}{1+1 / x}\left(1-\frac{1}{1+1 / x}\right) \\
& =\frac{a N \cdot x}{(1+x)^{2}}
\end{aligned} \\
& \frac{d \frac{\partial V}{\partial R}}{d x}=\frac{d \frac{\partial V}{\partial R}}{d R} \cdot \frac{d R}{d x}=\frac{d \frac{\partial V}{\partial R}}{d R} \cdot \frac{1}{a x}=a N \cdot \frac{1-x}{(1+x)^{3}} \\
& \frac{1}{a x}=\frac{b}{a} e^{-a R}>0
\end{aligned}
$$

Digitalization exceeding certain $\mathrm{R} \& \mathrm{D}$ level $(R>\ln b / a)$ results in productivity decline.

$$
\begin{aligned}
& \frac{d \frac{\partial V}{\partial R}}{d R}=0 \Leftrightarrow x=1 \Leftrightarrow R=\frac{\ln b}{a} \rightarrow R>\frac{\ln b}{a} \\
& \Rightarrow \frac{d \frac{\partial V}{\partial R}}{d x}<0
\end{aligned}
$$

Thus, $\frac{\ln b}{a}$ indicates inflection point in $S L G$ (see Note 2 ).

In particular innovation which creates new carrying capacity $N(R)$ during the process of diffusion, equation (7) is developed as follows:

$$
\frac{d V(R)}{d R}=a V(R)\left(1-\frac{V(R)}{N(R)}\right)
$$

Equation (12) develops the following logistic growth within a dynamic carrying capacity function $(L G D C C)$ which incorporates self-propagating function as carrying capacity increases corresponding to $V(R)$ increase as depicted in equation (14) (Watanabe et al., 2004):

$$
\begin{aligned}
& V_{L}(R)=\frac{N_{k}}{1+b e^{-a R}+\frac{b_{k}}{1-a_{k} / a} e^{-a_{k} R}} \\
& N_{L}(R)=V_{L}(R)\left(\frac{1}{1-\frac{1}{a} \cdot \frac{\Delta V_{L}(R)}{V_{L}(R)}}\right) \quad \Delta V_{L}(R)=\frac{d V_{L}(R)}{d R}
\end{aligned}
$$


Induced by this self-propagating function, functionality $(F D)$ spirally increases corresponding to $V(R)$ increase as depicted in equation (15):

$$
F D=\frac{N_{L}(R)}{V_{L}(R)}=\frac{1}{1-\frac{1}{a} \cdot \frac{\Delta V_{L}(R)}{V_{L}(R)}}
$$

As far as the development trajectory depends on $S L G$ trajectory, its digital value $\left(V_{S}(R)\right)$ saturates with upper limit depicted by fixed $N$ without self-propagating function, once the trajectory shifts to $L G D C C$, it can continue to increase supported by self-propagating function and led by dynamically enhancing upper limit $N_{L}(R)$.

Therefore, the magnitude of self-propagating function $(M S P F)$ can be estimated by the ratio of $N_{L}(R)$ and $V_{S}(R)$ as follows (Watanabe et al., 2017b):

$M S P F=\frac{N_{L}(R)}{V_{S}(R)}=\frac{V_{L}(R)}{V_{S}(R)} \cdot\left(\frac{1}{1-\frac{1}{a} \cdot \frac{V_{L}(R)}{V_{L}(R)}}\right)$

\section{Note 2 Inflection point in $L G D C C$}

$L G D C C$ function by equation (13) can be approximated by the following $S L G$ function (Watanabe et al., 2009)

$$
\begin{aligned}
& V_{L}(R)=\frac{N_{k}}{1+b e^{-a R}+\frac{b_{k}}{1-a_{k} / a} e^{-a_{k} R}} \approx \frac{N_{k}}{1+b^{\prime e^{-a^{\prime} R}}} \\
& a^{\prime}=a\left(1-\frac{b_{k}}{b}\right), b^{\prime}=b\left(1+\frac{b_{k}}{b} \cdot \frac{1}{1-\frac{a_{k}}{a}}\right) \quad b^{\prime e^{-a^{\prime} R}} \equiv \frac{1}{x} \\
& \frac{\partial V_{L}}{\partial R}=a^{\prime N_{k}} \frac{x}{(1+x)^{3}}, \frac{d \frac{\partial V_{L}}{\partial R}}{d x}=\frac{d \frac{\partial V_{L}}{\partial R}}{d R} \cdot \frac{1}{a^{\prime} x}=a^{\prime} N_{k} \cdot \frac{(1-x)}{(1+x)^{3}}, \\
& \frac{d \frac{\partial V_{L}}{\partial R}}{d R}=0 \text { when } x=1\left(R=\frac{\ln b^{\prime}}{a^{\prime}}\right) \\
& \text { Therefore } \frac{d \frac{\partial V_{L}}{\partial R}}{d R}<0 \\
& \text { when } R>\frac{\ln b^{\prime}}{a^{\prime}} \approx \frac{\ln b\left(1+\frac{b_{k}}{b} \cdot \frac{1}{1-\frac{a_{k}}{a}}\right)}{a\left(1-\frac{b_{k}}{b}\right)}>\frac{\ln b}{a}
\end{aligned}
$$

Inflection level in $L G D C C$ is higher than that of in $S L G$ function without self-propagating function.

\section{Note 3 Assessment of self-propagating function}

As reviewed in Section 2.2, ICT incorporates self-propagating potential. This potential can be measured by equation (14) which is governed by the growth rate and the level of development trajectory $\left(V_{L}(R)\right)$. This level in $L G D C C$ is identified by the third term of the denominator of equation (13). This term constitutes $S L G$ function in which a coefficient $a_{k}$ plays a significant role in determining the initial level and 